\title{
Polymer Composites Containing Functionalized Nanoparticles and the Environment
}

Jamal Seyyed (Name: Jamal; Surname: Seyyed Monfared Zanjani)Monfared Zanjani ${ }^{1,2}$

Oguzhan Oguz ${ }^{1,2}$

Burcu Saner Ok (Name: Burcu; Surname:Saner Okan)an ${ }^{1,2}$

Mehmet Yildiz ${ }^{1,2}$

Yusuf Ziya Menceloglu ${ }^{1,2}$

${ }^{\mathbf{1}}$ Faculty of Engineering and Natural Sciences, Materials Science and Nano Engineering, Sabanci University, Orhanli, Tuzla, Istanbul, Turkey

${ }^{2}$ Sabanci University Integrated Manufacturing Technologies Research and Application Center \& Composite Technologies Center of Excellence, Teknopark Istanbul, Pendik, Istanbul, Turkey

\subsection{Introduction}

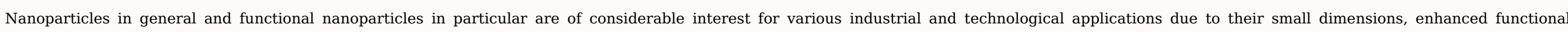

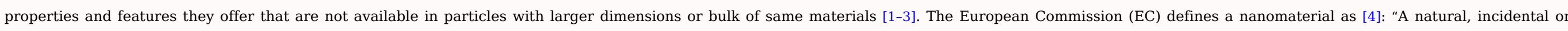

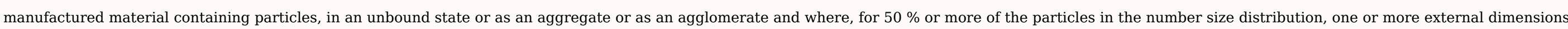

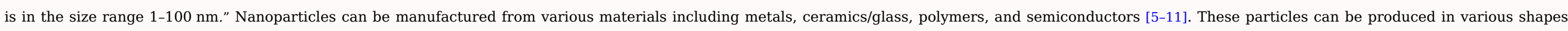

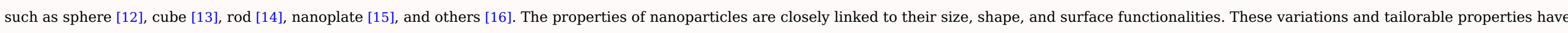

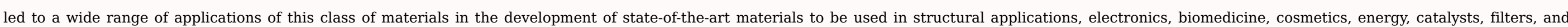

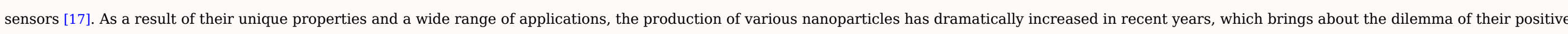

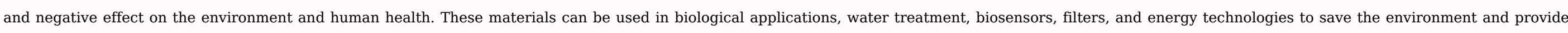
higher life quality for humankind. However, even nanoparticles synthesized from biologically inert materials can be harmful to

the cell by damaging cell membrane, disrupting cell function, or altering the genetics of the cell by attaching to its DNA [18].

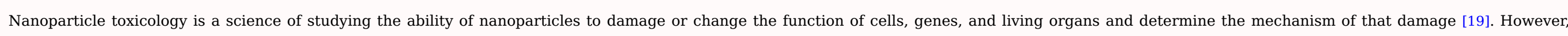

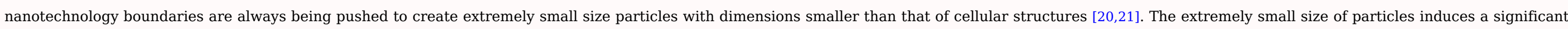




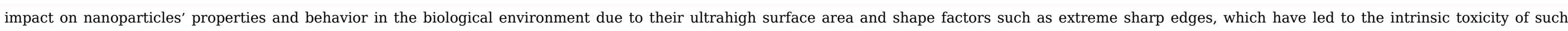

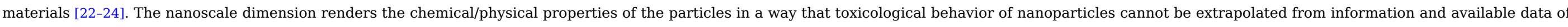
larger particles of the same composition [24,25].

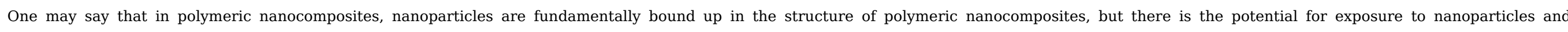

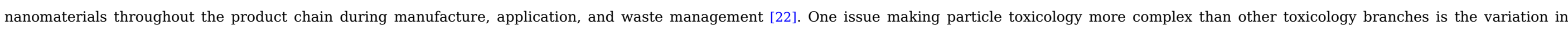
behavior of nanoparticles of interest by several structural and environmental factors that enable the unfavorable effect of nanoparticles in diverse scenarios [22].

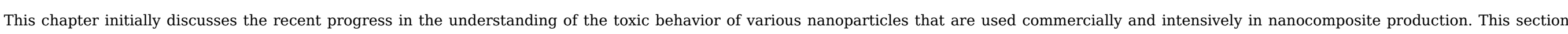

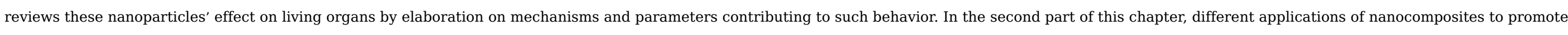
human quality of life and contributing to the wellbeing of the environment are discussed in selected areas to emphasize the importance of nanocomposites in technological advancements.

\subsection{Toxicological and Exposure}

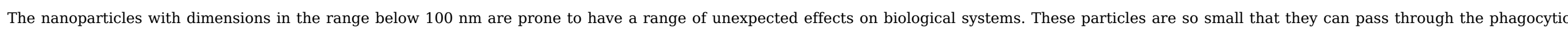

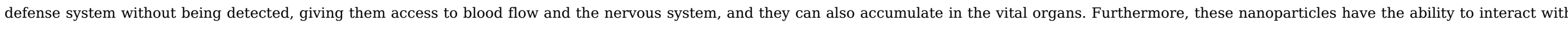

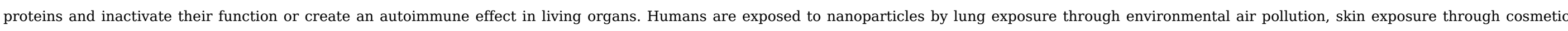

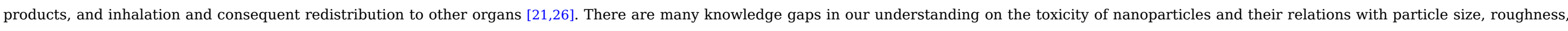

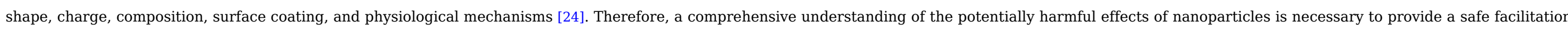
of these materials to our

Page 431

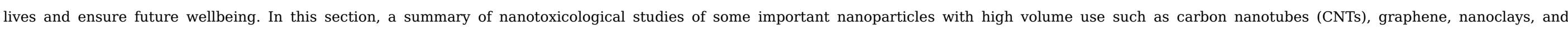

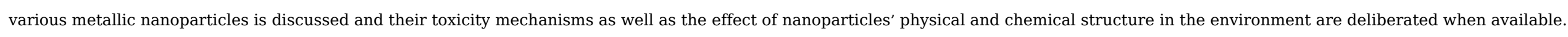

\subsubsection{Carbon Nanotubes}

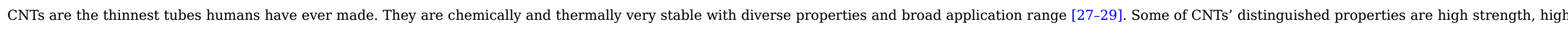

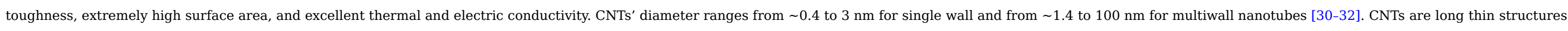

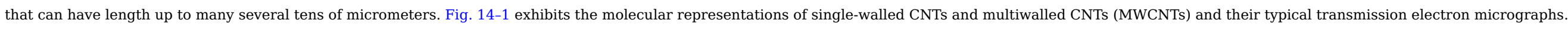

(A)
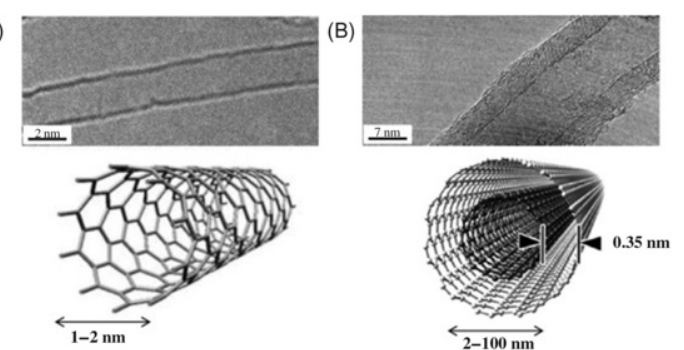

Figure 14-1 TEM images and schematic illustrations of CNT types showing typical diameters and separation between the graphene layers in MWCNT: (A) single-walled carbon nanotube (SWCNT) and (B) MWCNT. 


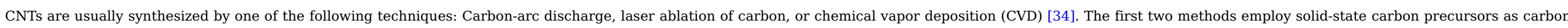

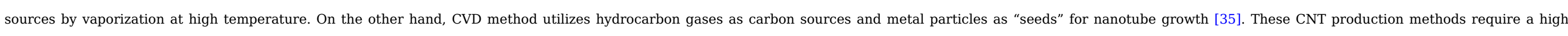

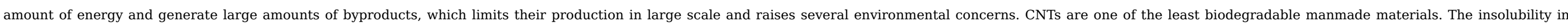

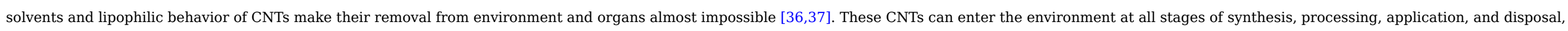

Page 432

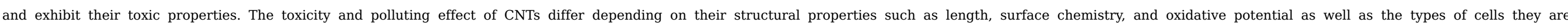
interacting with [38].

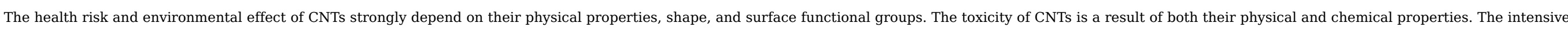

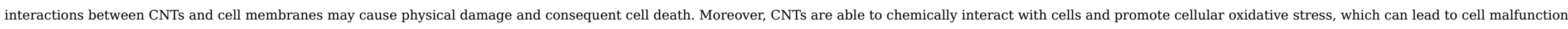

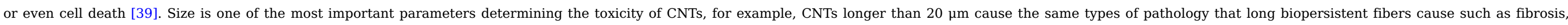

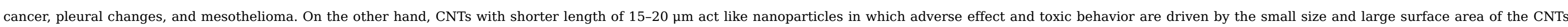

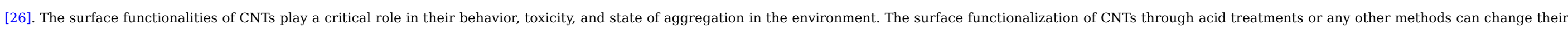

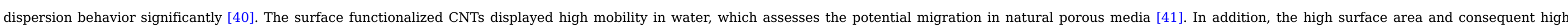

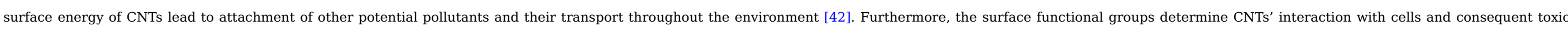

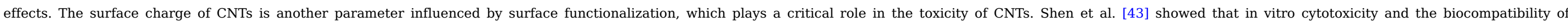

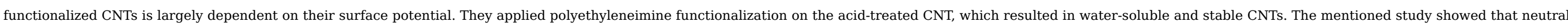

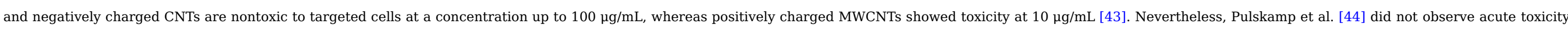

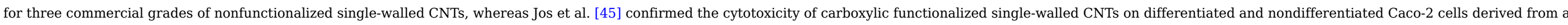

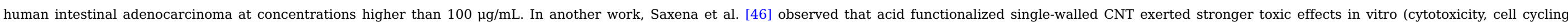

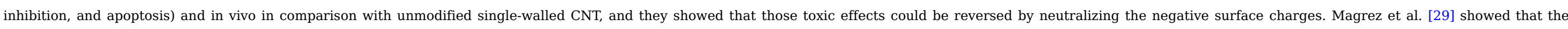

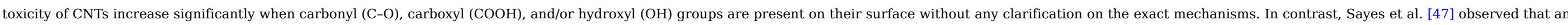
increase in the degree of sidewall functionalization of single-walled CNTs decreases their cytotoxic property.

In general, size, shape, and surface charge of nanoparticles are believed to be the three most important factors affecting the nanoparticles' toxicity. However, the toxic behavior of

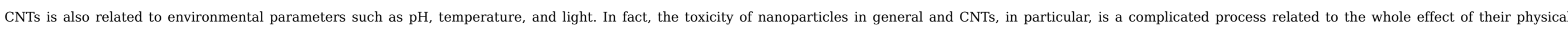

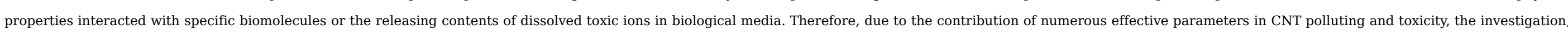

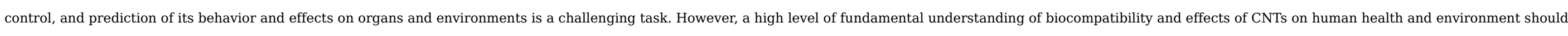

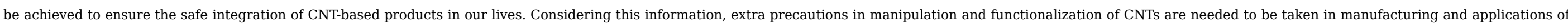




\subsubsection{Graphene}

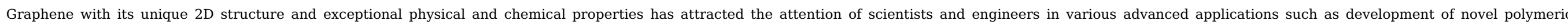

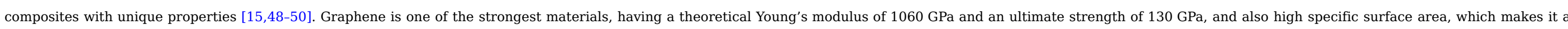

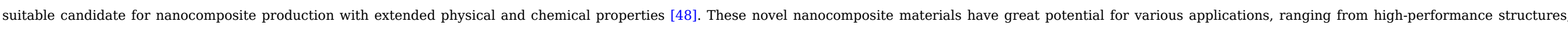
energy storage devices, electrically conductive polymeric materials, as well as antibacterial materials [51].

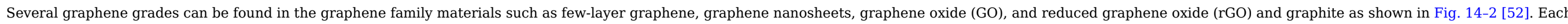

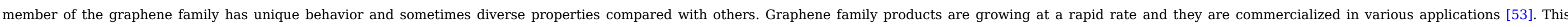

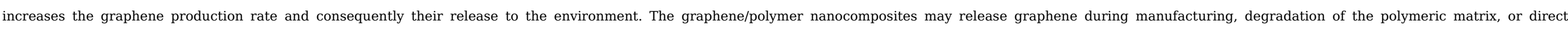

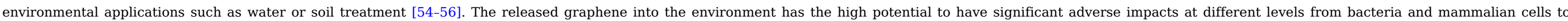
animals.

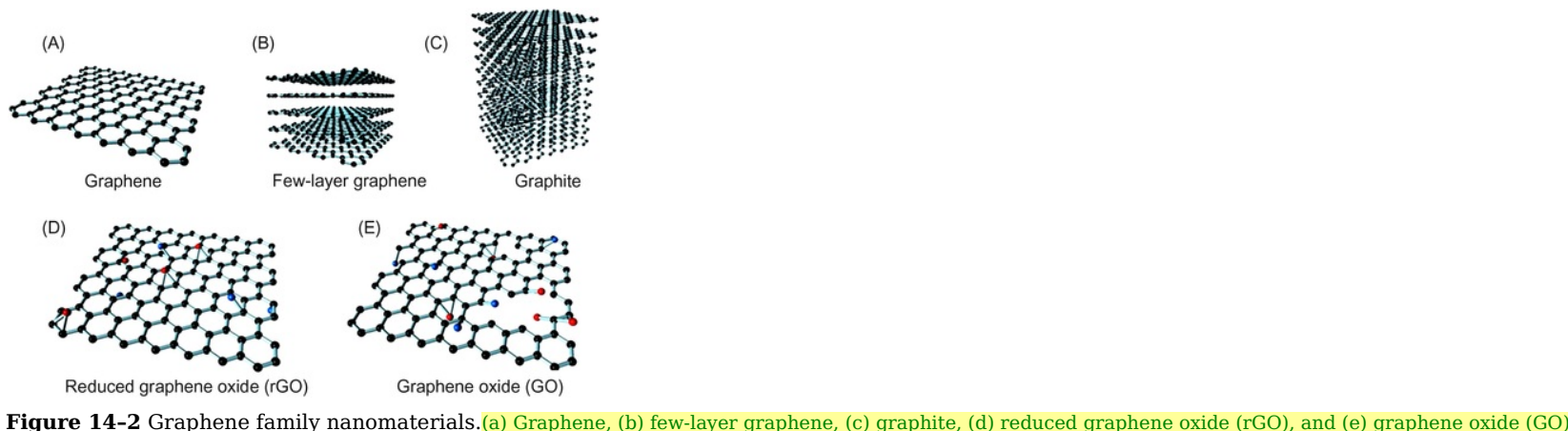

Reprinted from Kiew SF, Kiew LV, Lee HB, Imae T, Chung LY. Assessing biocompatibility of graphene oxide-based nanocarriers: a review. J Control Release 2016;226:217-28, by permission of Elsevier

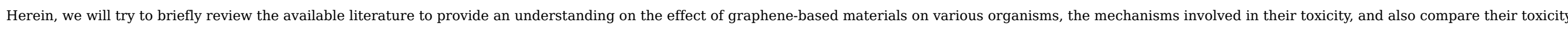

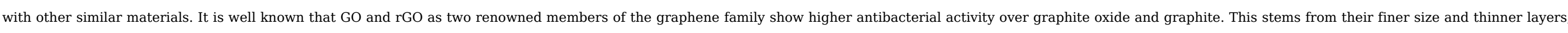
which give them the sharp edges to damage the plasma membranes on bacterial cells and kill the cell [39,57]. The sharp edges of GO and rGO are not available in other carbon

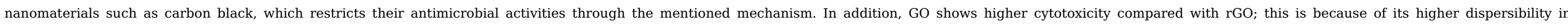

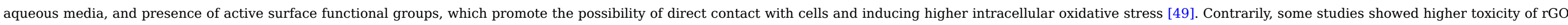

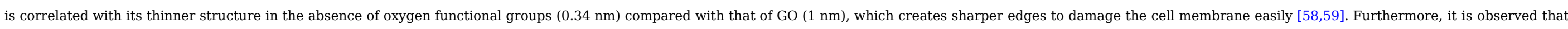

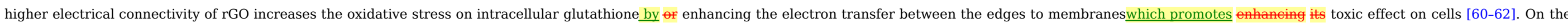
other hand, the hydrophobicity of rGO upholds its interaction with the cells' outer wall, which can hinder the nutrient absorption and gas exchange across the cell membrane [63,64].

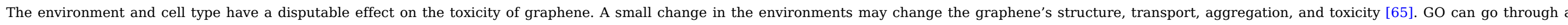

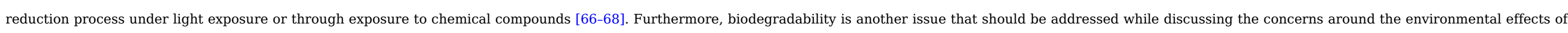




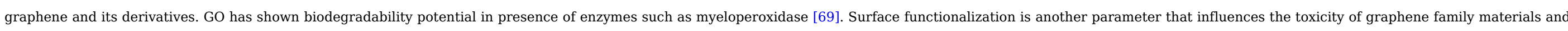

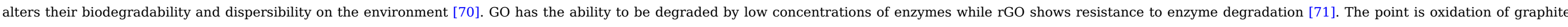

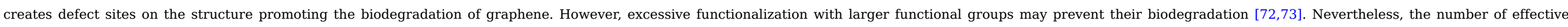
enzymes to be used in

Page 435

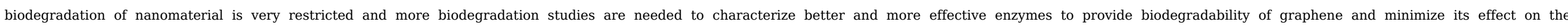
ecosystem [70].

\subsubsection{Nanoclays}

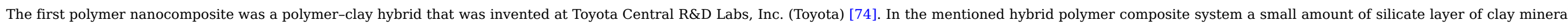

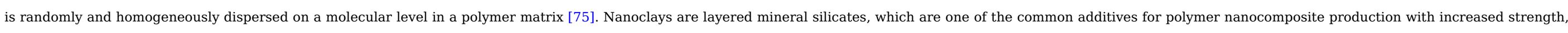
modulus, and toughness and improved barrier and flame-retardant properties [76,77]. Clay-based polymeric nanocomposites possess a large portion of the nanocomposite market in various application areas.

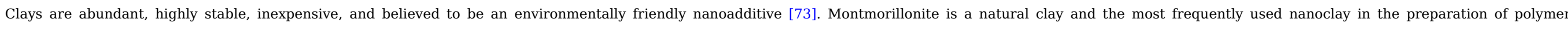

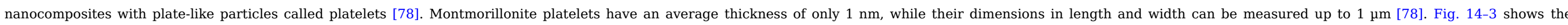

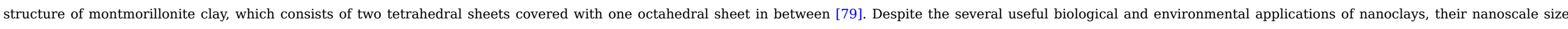

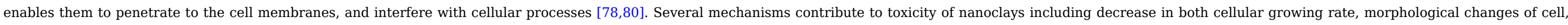
cellular proliferation, mitochondrial damage, reactive oxygen species generation, and

\section{Page 436}

DNA alteration [81-84]. It worth noting that the prudency of each damage type is closely related to studied cell, dosage, and surface functionalization of clays.

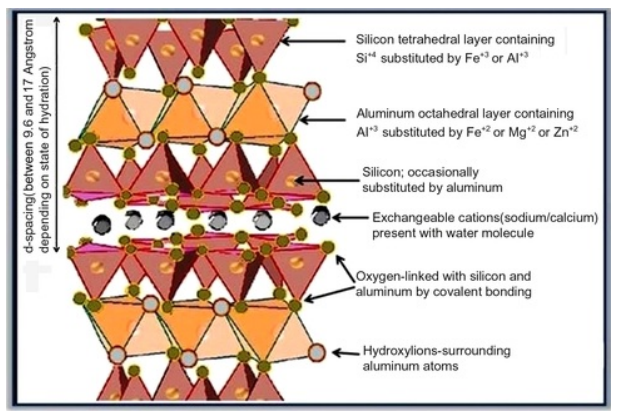

Figure 14-3 Structural unit of montmorillonite nanoclay.

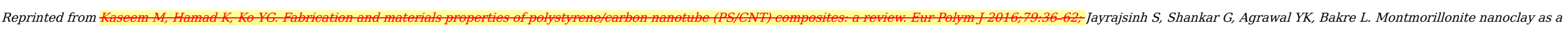
multifaceted drug-delivery carrier: a review. J Drug Deliv Sci Technol 2017;39(Suppl. C):200-9, by permission of Elsevier. 


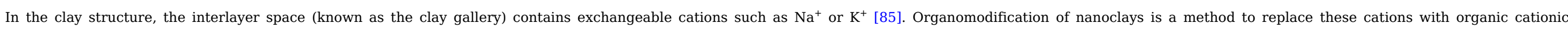

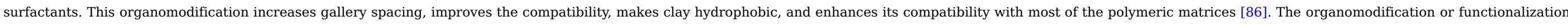

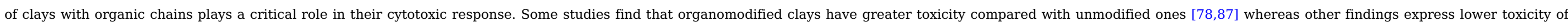
modified clays compared with their unmodified counterparts [88,89]. These studies also express the importance of functional group type used for organomodification on the toxicity of nanoclays [90-92].

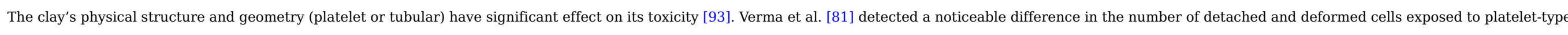

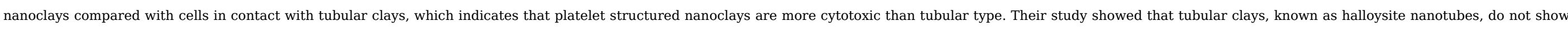
any toxic effect until doses of $250 \mu \mathrm{g} / \mathrm{mL}$, while platelet nanoclays cause toxicity at $25 \mu \mathrm{g} / \mathrm{mL}$ [81].

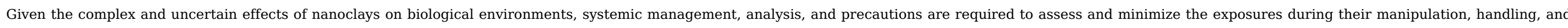

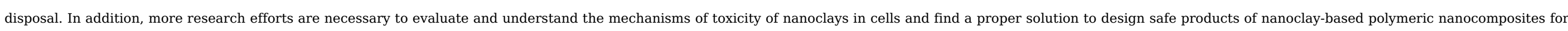
future applications.

\subsubsection{Metal Nanoparticles}

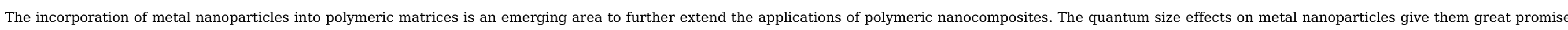

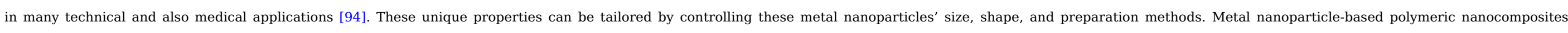

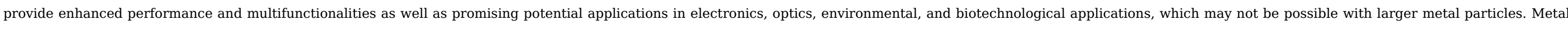

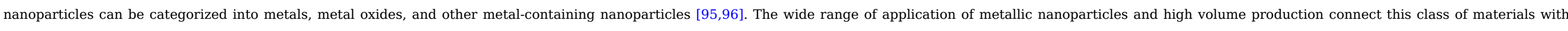

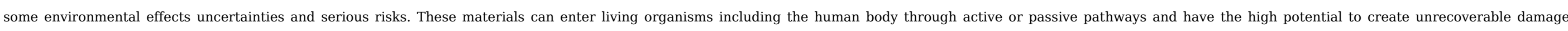
because of their activated toxicity due to their intrinsic properties and also their nanoscale size [97]. In this part, the

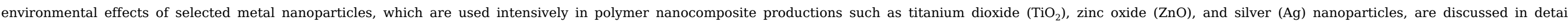
including the effective parameters and corresponding mechanisms in their toxicity.

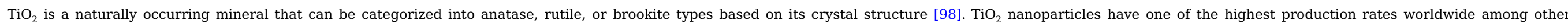

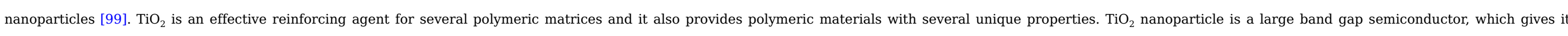

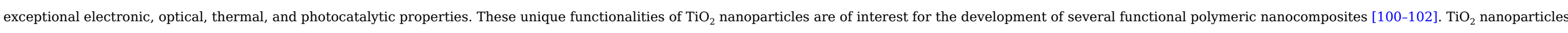

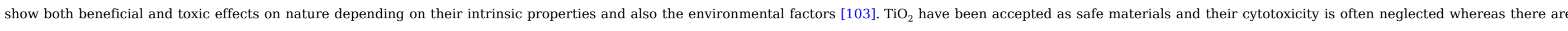

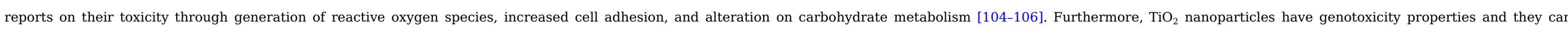

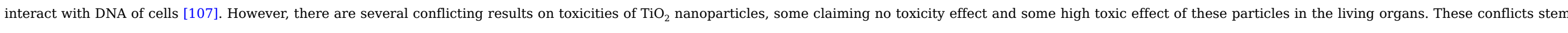

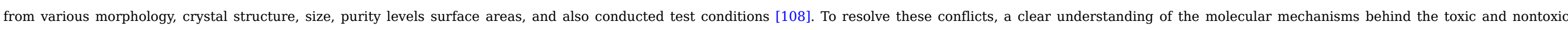
responses of $\mathrm{TiO}_{2}$ nanoparticles is needed [104].

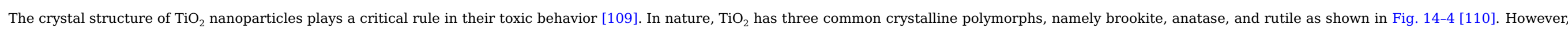
only rutile and anatase $\mathrm{TiO}_{2}$ are generally manufactured in titanium dioxide commercial applications. The relative toxicity of each 


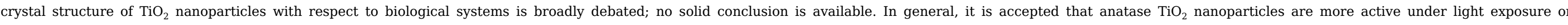

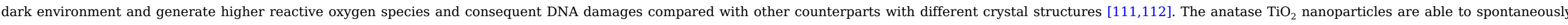

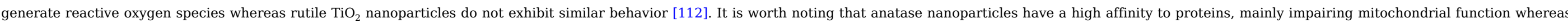

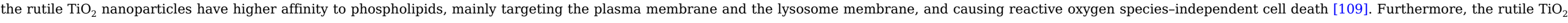

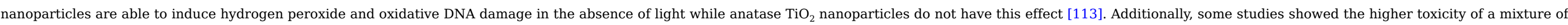
anatase and rutile particles and its higher abilities to create DNA damage in the absence of light compared with individual anatase or rutile $\mathrm{TiO}_{2}$ due to contribution of multiple toxicity mechanisms [113].

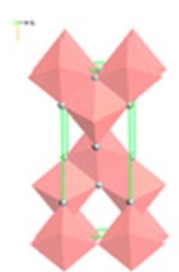

(A)

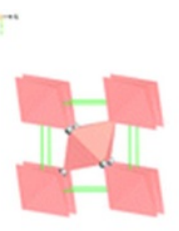

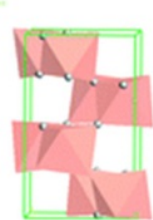

Figure 14-4 Representation of three $\mathrm{TiO}_{2}$ polymorphs: (A) anatase, (B) rutile, and (C) brookite forms.

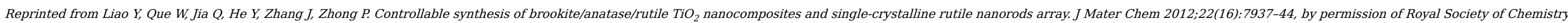

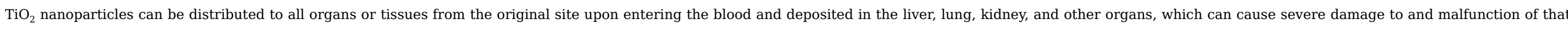

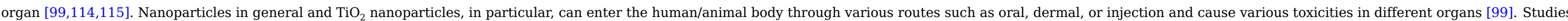

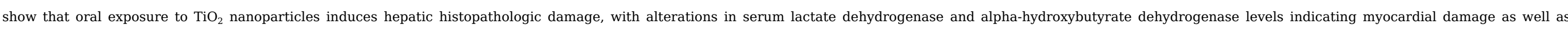

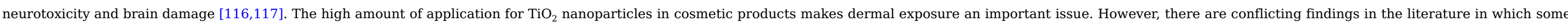

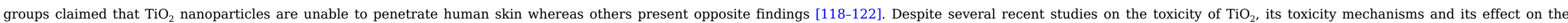

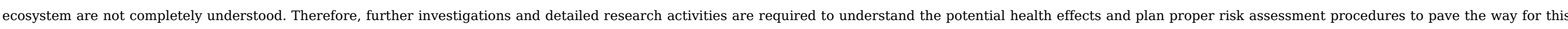
useful material implementation in future applications.

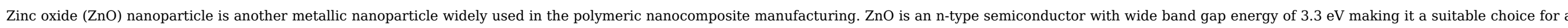

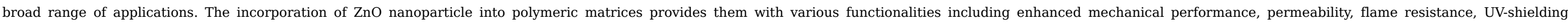

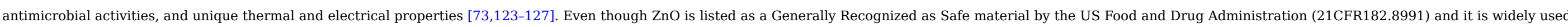

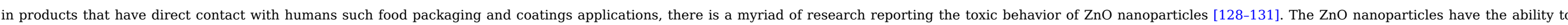
induce morphological modifications, oxidative stress, lipid

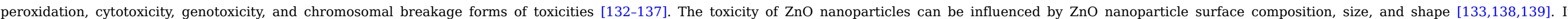

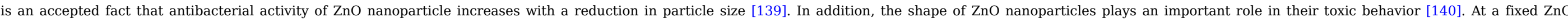

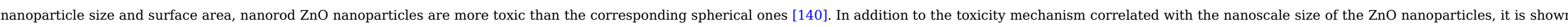




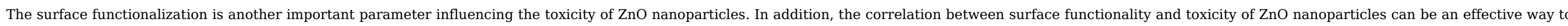

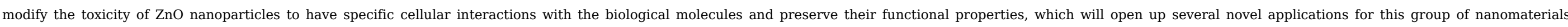

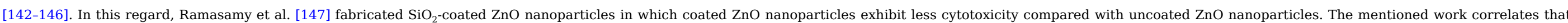

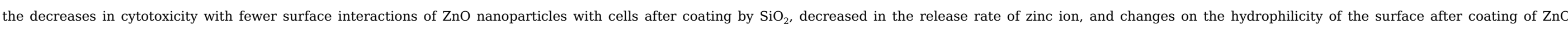

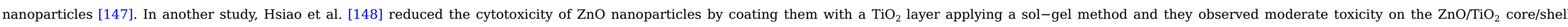

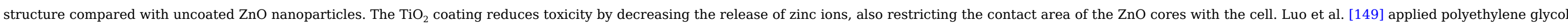

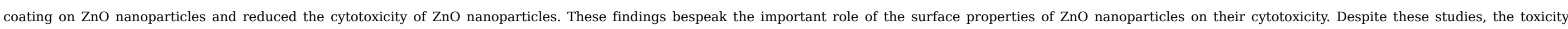

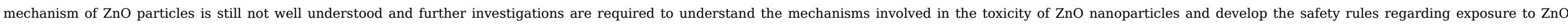
nanoparticles.

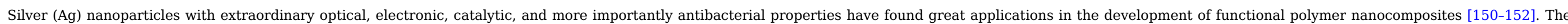

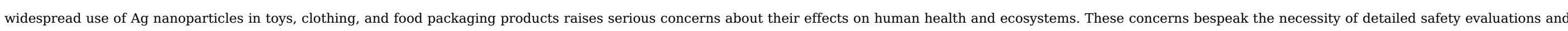

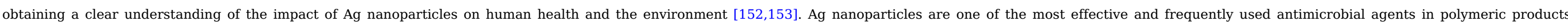

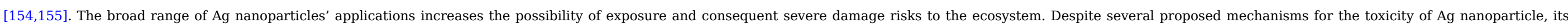
exact mechanisms are not well understood yet [156]. Some of the proposed mechanisms

Page 440

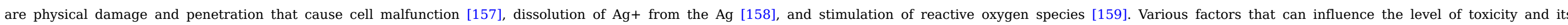

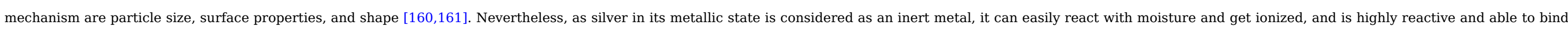
to proteins, DNA, and RNA [162].

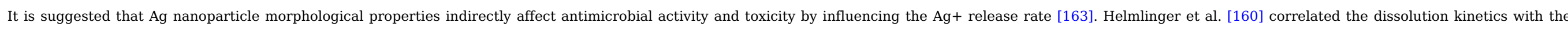

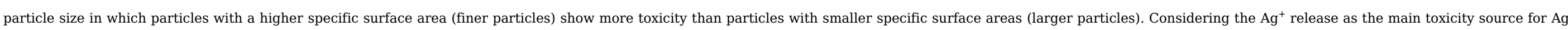

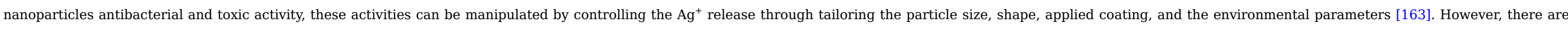

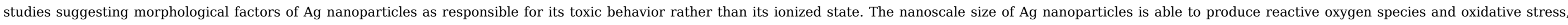

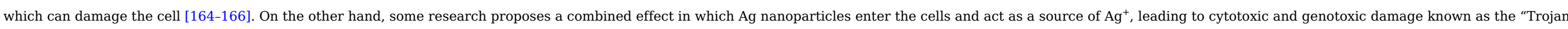

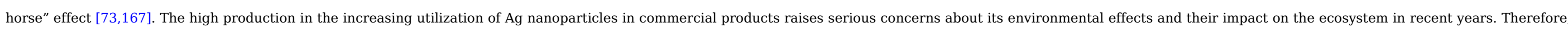
more research and investigations are needed to enhance current understanding of their toxic behavior and address these issues for their further development.

\subsection{Environmental Benefits and Application of Polymeric Nanocomposites}

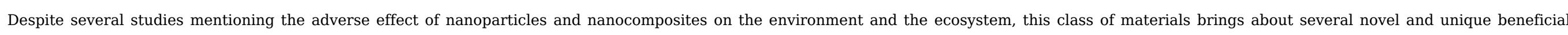

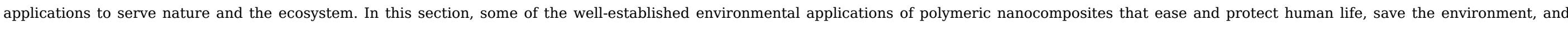

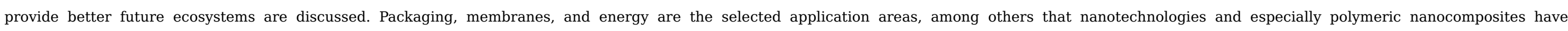
revolutionized.

\subsubsection{Food Packaging by Nanotechnology and Nanocomposites}




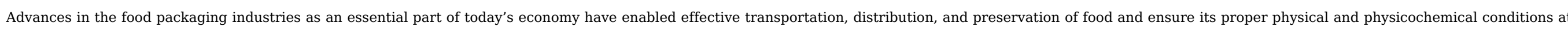

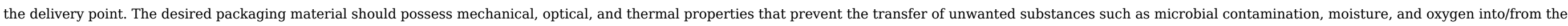

Page 441

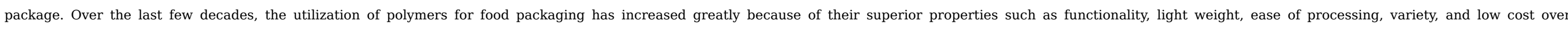

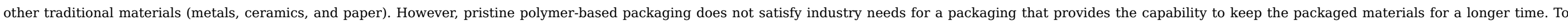

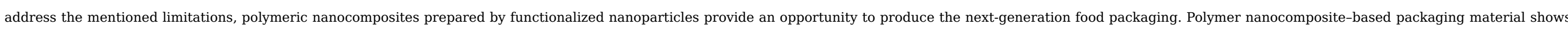

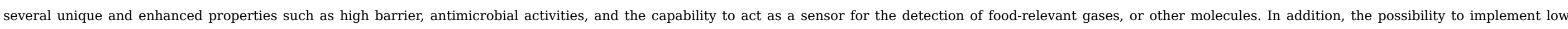

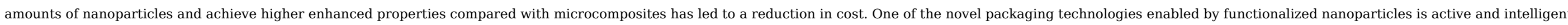

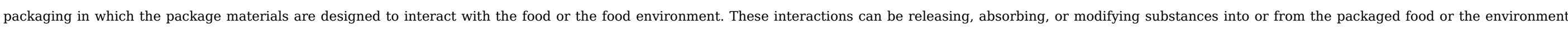

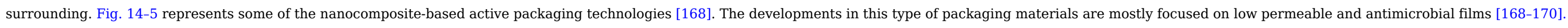

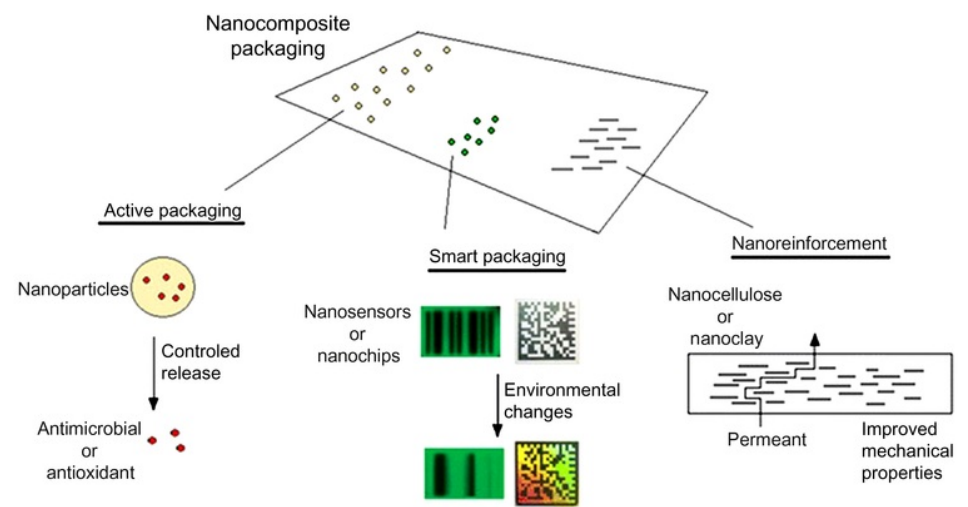

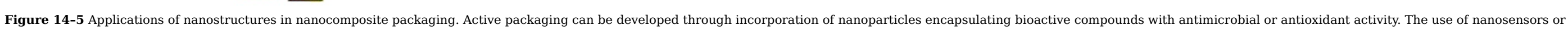

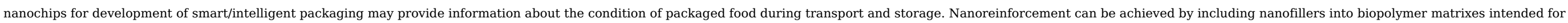
packaging purposes, providing significant improvements in mechanical and barrier properties.

Reprinted from Brandelli A, Brum LFW, dos Santos JHZ. Nanostructured bioactive compounds for ecological food packaging. Environ Chem Lett 2017;15(2):193-204, by permission of Springer Nature.

Page 442

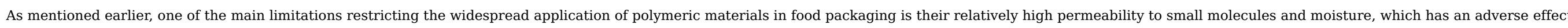

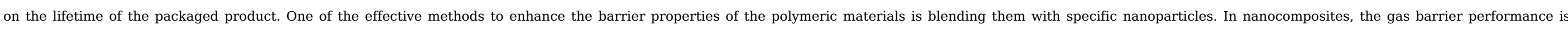

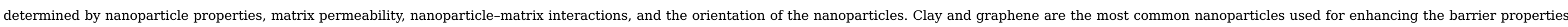

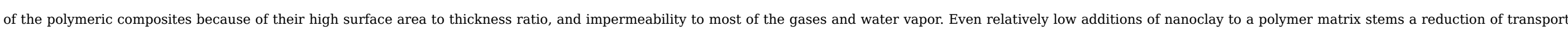

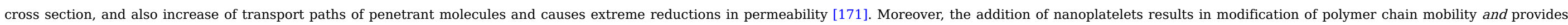




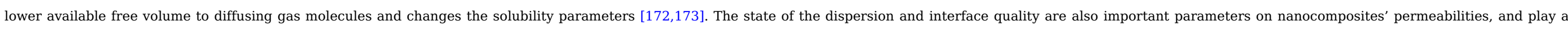

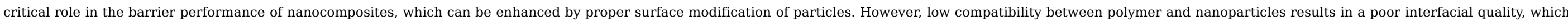

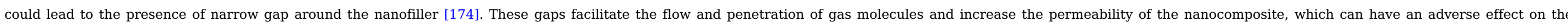

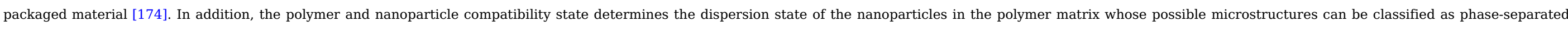
(microcomposite), intercalated, and exfoliated as shown in Fig. 14-6 [175]. In the case of phase-

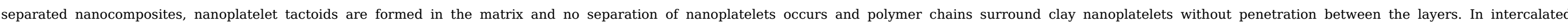

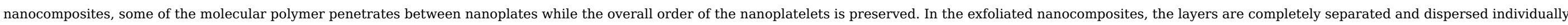

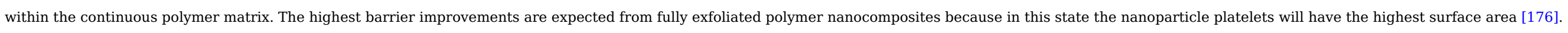

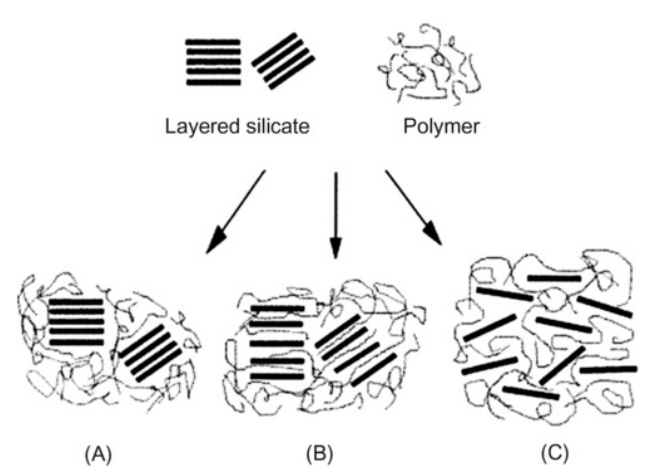

Figure 14-6 Scheme of different types of composite arising from the interaction of layered silicates and polymers: (A) phase-separated microcomposite, (B) intercalated nanocomposite, and (C) exfoliated nanocomposite.

Reprinted from Alexandre M, Dubois P. Polymer-layered silicate nanocomposites: preparation, properties and uses of a new class of materials. Mater Sci Eng Rep 2000;28(1):1-63, by permission of Elsevier.

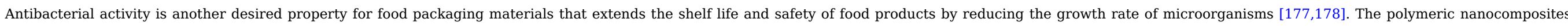

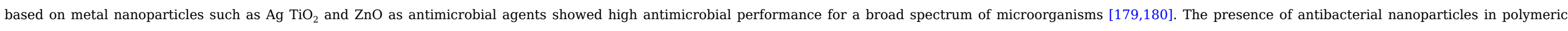

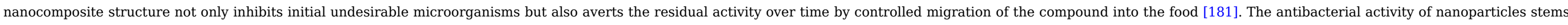

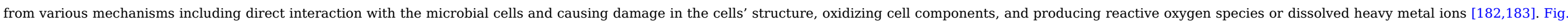
14-7 shows various mechanisms of antimicrobial activities exerted by nanomaterials [182]. 


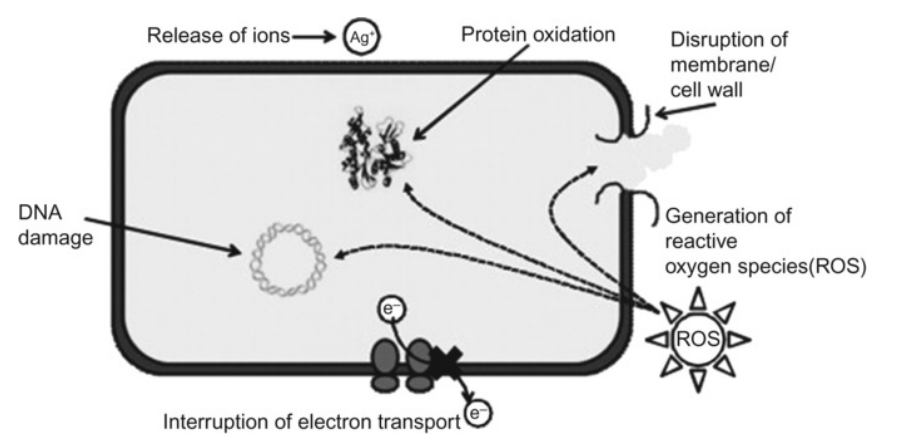

Figure 14-7 Various mechanisms of antimicrobial activities exerted by nanomaterials.

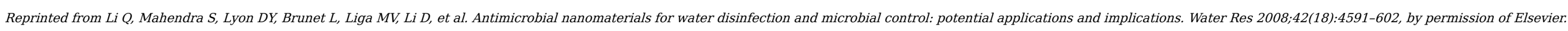

\subsubsection{Nanocomposites in Membrane Technology}

Membrane technology is widely applied in various industries such as water treatment, molecular separations, biomolecule purification, environmental remediation, gas separation,

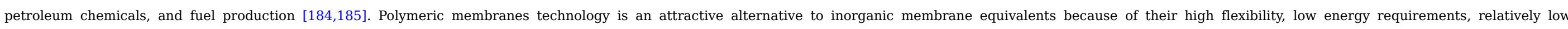

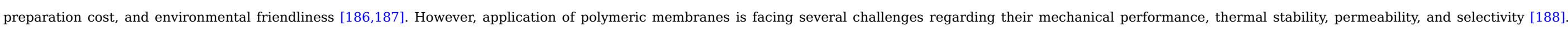

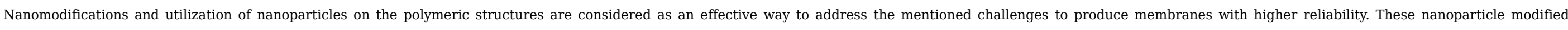

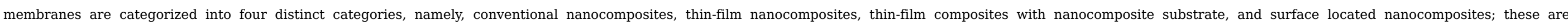

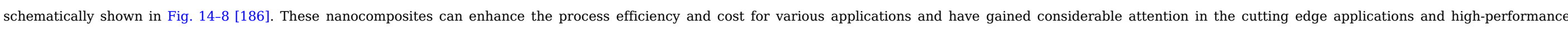
membrane production in fuel cells, proton exchange membrane, sensors, batteries, solvents, and water treatment [189].

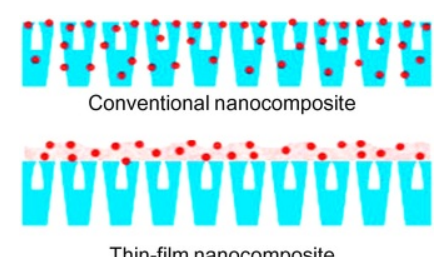

Thin-film nanocomposite

BWHF以ด

TFC with nanocomposite substrate

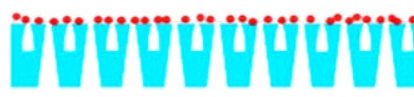

Surface located nanocomposite

Figure 14-8 Typical types of nanocomposite membranes $T F C$, Thin-film composite.

Reprinted from Yin J, Deng B. Polymer-matrix nanocomposite membranes for water treatment. J Memb Sci 2015;479:256-75, by permission of Elsevier. 


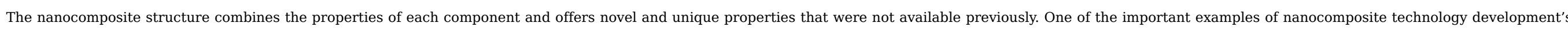

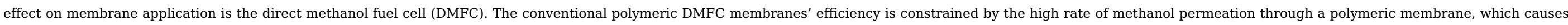
the chemical reaction of the fuel with oxygen and depolarization of the cathode [190]. Therefore, it is highly desirable to have a membrane with reduced methanol

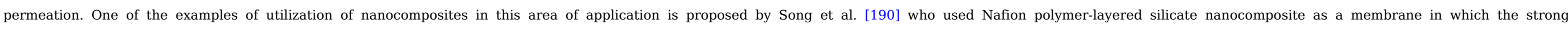

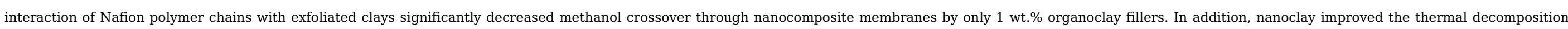
temperature and mechanical properties of the Nafion-based membrane [190].

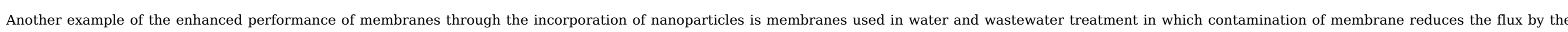

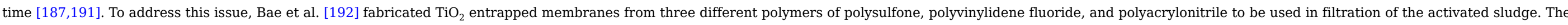

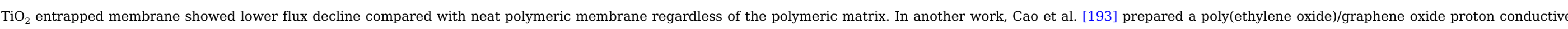

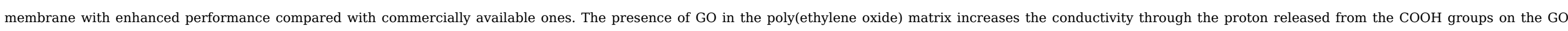

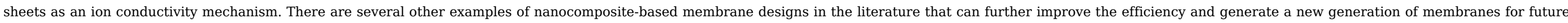
applications in energy and various environmental applications, which can boost the future view of our ecosystem.

\subsubsection{Nanocomposites in Energy Applications}

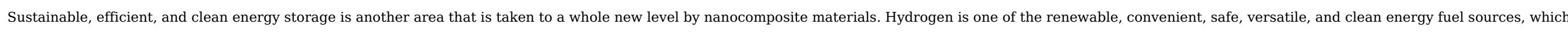

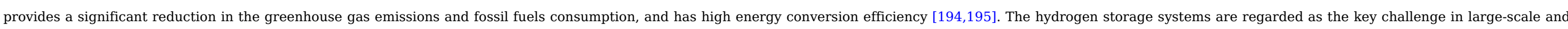

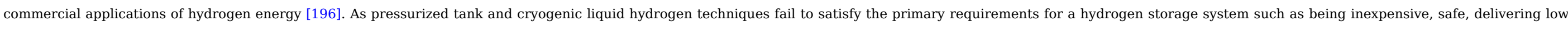
efficiency, and material-based storage systems are expected to provide a final solution for this issue [196,197]

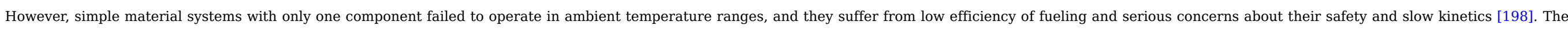

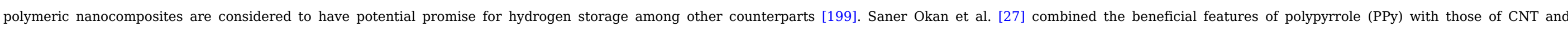

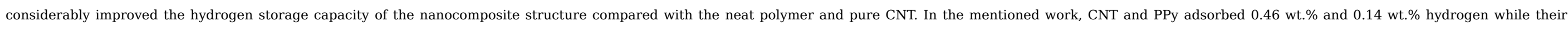

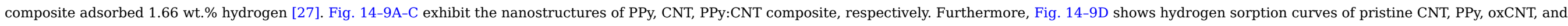



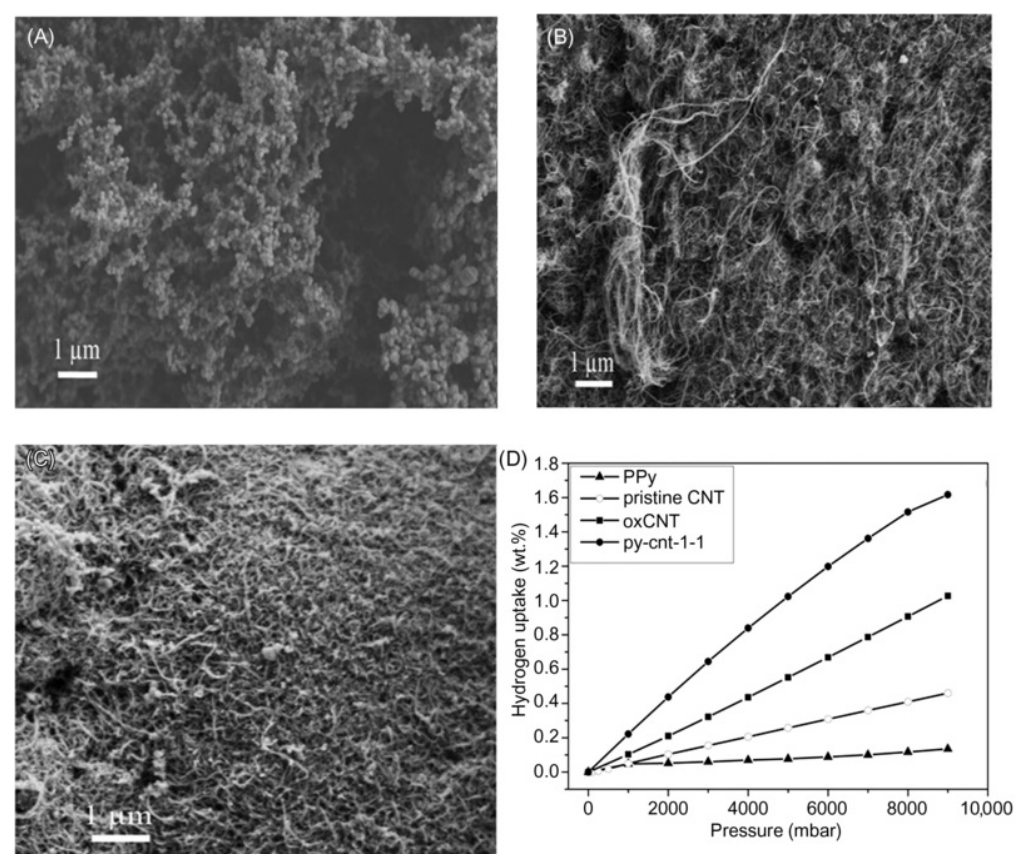

Figure 14-9 SEM images of (A) pristine PPy, (B) pristine CNT, (C) Py:CNT=1:1 composite, and (D) the comparison of adsorption isotherms of pristine CNT, PPy, oxCNT, and Py:CNT=1:1.

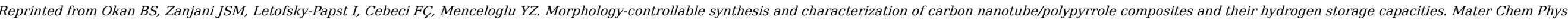
2015;167(Suppl. C):171-80, by permission of Elsevier

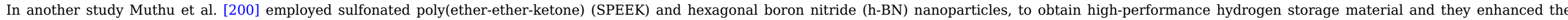

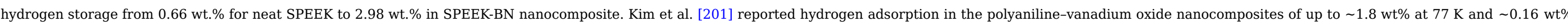
at $298 \mathrm{~K}$ whereas neither polyaniline $(\sim 0.2 \mathrm{wt} \%$ at $77 \mathrm{~K})$ nor pristine vanadium

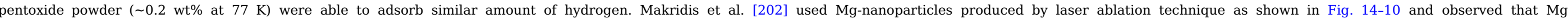

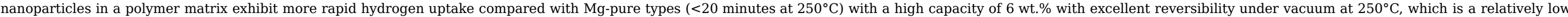
temperature with regard to the necessary $\sim 330^{\circ} \mathrm{C}$ for Mg-bulk materials. These studies bespeak the high potential of nanocomposites for hydrogen storage in the near future 


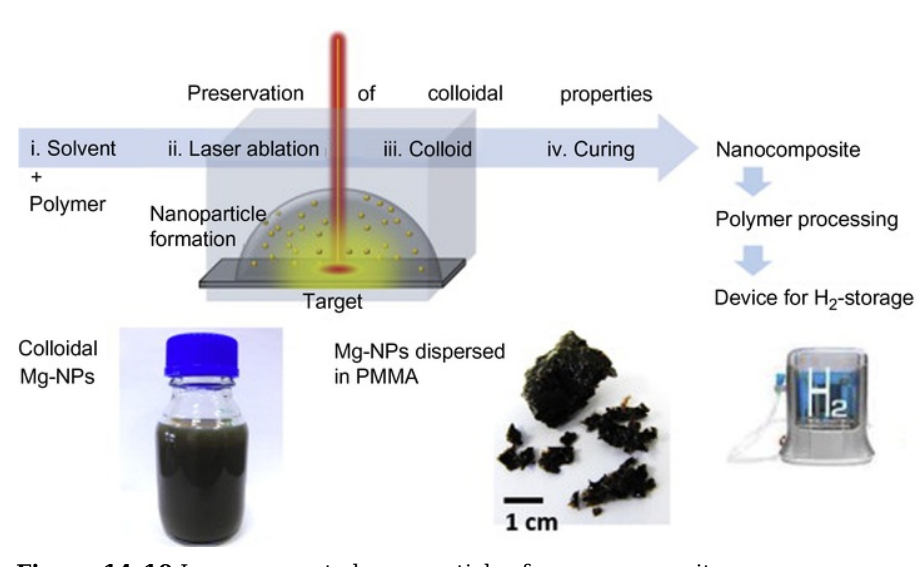

Figure 14-10 Laser-generated nanoparticles for nanocomposites.

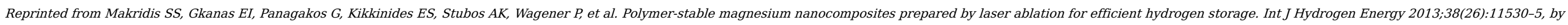
permission of Elsevier.

\subsection{Conclusion and Outlook}

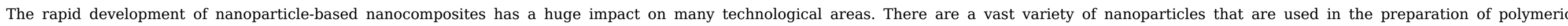

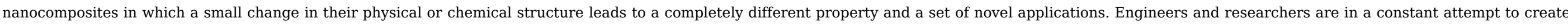

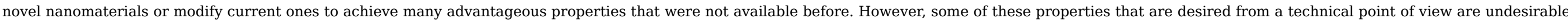

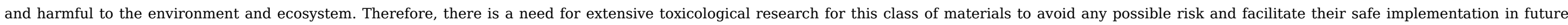
products. The first part of this chapter provides a short review on the

Page 448

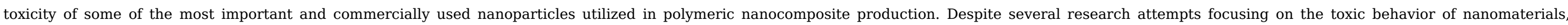

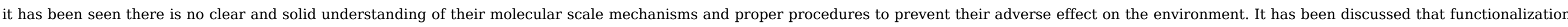

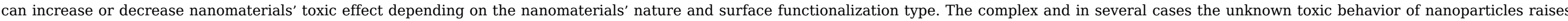

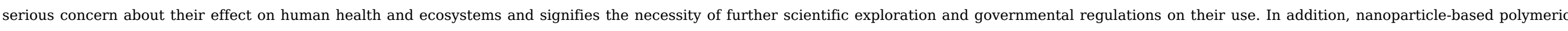

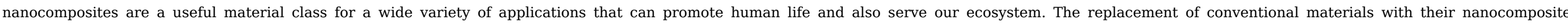

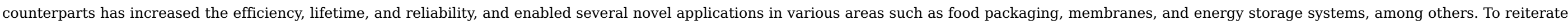

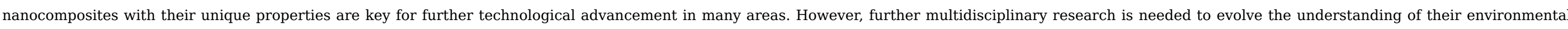
effects and produce nanocomposites with minimum adverse effect on the ecosystem.

\section{References}

[1] S. Lordan and C.L. Higginbotham, Effect of serum concentration on the cytotoxicity of clay particles, Cell Biol Int 36 (1), 2012 , 57-61.

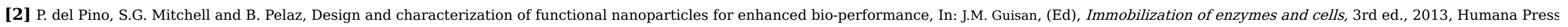
Totowa, NJ, 165-207. 


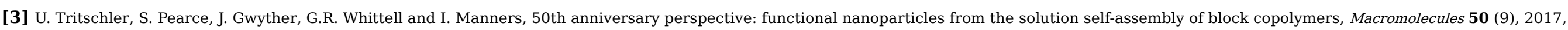
3439-3463.

[4] The EU Commission Recommendation on the Definition of Nanomaterial E, European Commission, Brussels; 2011.

[5] Sreeprasad TS, Pradeep T. Noble metal nanoparticles. In: Vajtai R, editor. Springer handbook of nanomaterials. Berlin, Heidelberg; 2013. p. 303-388.

[6] C.T. Shindu, Harshita, M. Pawan Kumar and T. Sushama, Ceramic nanoparticles: fabrication methods and applications in drug delivery, Curr Pharm Des 21 (42), 2015, 6165-6188.

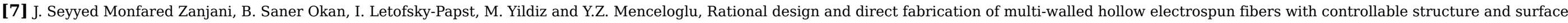
properties, Eur Polym J 62, 2015, 66-76.

[8] M. Bangal, S. Ashtaputre, S. Marathe, A. Ethiraj, N. Hebalkar, S.W. Gosavi, et al., Semiconductor nanoparticles, Hyperfine Interact 160 (1), 2005 , 81-94.

[9] Zanjani Jamal Seyyed M, Okan Burcu S, Menceloglu Y, Yildiz M. Self-healing thermosetting composites: concepts, chemistry, and future advances.

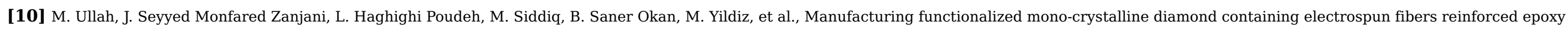
composites with improved mechanical characteristics, Diam Relat Mater 76, 2017, 90-96.

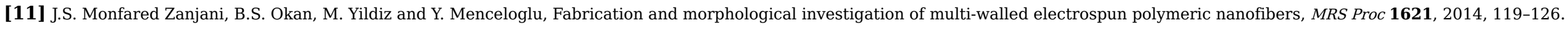

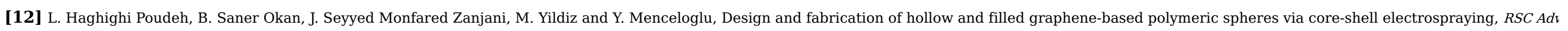
5 (111), 2015, 91147-91157.

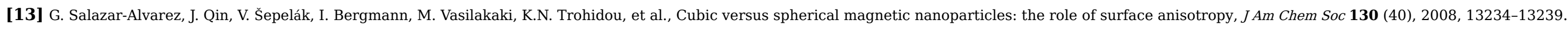

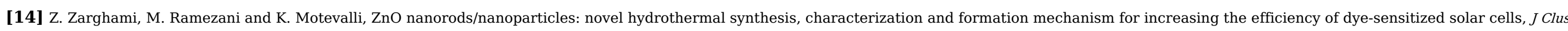
SCi 27 (4), 2016, 1451-1462.

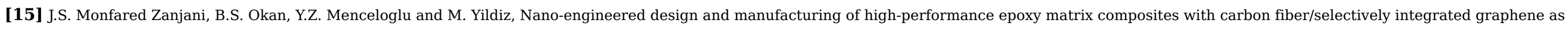
multi-scale reinforcements, RSC Adv 6 (12), 2016, 9495-9506.

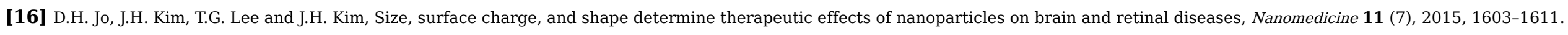

[17] W.-T. Liu, Nanoparticles and their biological and environmental applications, J Biosci Bioeng 102 (1), 2006, 1-7.

[18] M. Tsoli, H. Kuhn, W. Brandau, H. Esche and G. Schmid, Cellular uptake and toxicity of Au55 clusters, Small 1 (8-9), 2005, 841-844.

[19] K. Donaldson and A. Seaton, A short history of the toxicology of inhaled particles, Part Fibre Toxicol 9, 2012, 13.

[20] K. Donaldson, V. Stone, A. Clouter, L. Renwick and W. MacNee, Ultrafine particles, Occup Environ Med 58 (3), $2001,211$.

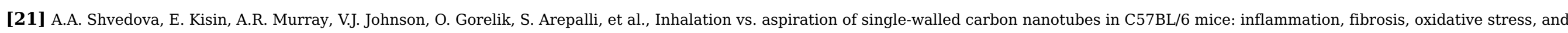
mutagenesis, Am J Physiol Lung Cell Mol Physiol 295 (4), 2008, L552-L565.

[22] K. Donaldson, V. Stone, C.L. Tran, W. Kreyling and P.J.A. Borm, Nanotoxicology, Occup Environ Med 61 (9), $2004,727$. 
[23] C.L. Tran and DBRTCASADJKD, Inhalation of poorly soluble particles. II. influence of particle surface area on inflammation and clearance, Inhal Toxicol 12 (12), 2000, 1113-1126.

[24] L.E. Ogden, Nanoparticles in the environment: tiny size, large consequences?, Bioscience 63 (3), 2013, 236.

[25] A.M. Knaapen, P.J.A. Borm, C. Albrecht and R.P.F. Schins, Inhaled particles and lung cancer. Part A: Mechanisms, Int J Cancer 109 (6), $2004,799-809$.

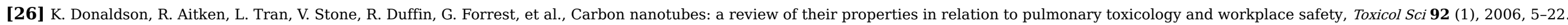

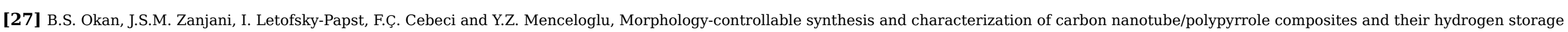
capacities, Mater Chem Phys 167 (Suppl. C), 2015, 171-180.

[28] M. Yumura, Carbon nanotube industrial applications, AIST Today (Int Ed) 10, 2003, 8-9.

[29] F. Lu, L. Gu, M.J. Meziani, X. Wang, P.G. Luo, L.M. Veca, et al., Advances in bioapplications of carbon nanotubes, Adv Mater 21 (2), 2009, 139-152.

[30] R. Ding, G. Lu, Z. Yan and M. Wilson, Recent advances in the preparation and utilization of carbon nanotubes for hydrogen storage, J Nanosci Nanotechnol 1 (1), 2001, 7-29.

[31] Z. Tang, L. Zhang, N. Wang, X. Zhang, G. Wen, G. Li, et al., Superconductivity in 4 angstrom single-walled carbon nanotubes, Science 292 (5526), $2001,2462-2465$.

[32] R.H. Baughman, A.A. Zakhidov and W.A. de Heer, Carbon nanotubes-the route toward applications, Science 297 (5582), $2002,787$.

[33] M. Kaseem, K. Hamad and Y.G. Ko, Fabrication and materials properties of polystyrene/carbon nanotube (PS/CNT) composites: a review, Eur Polym J 79, $2016,36-62$.

[34] H. Dai, Carbon nanotubes: synthesis, integration, and properties, Acc Chem Res 35 (12), 2002, 1035-1044.

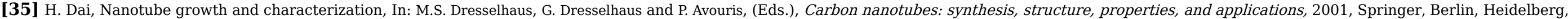
29-53.

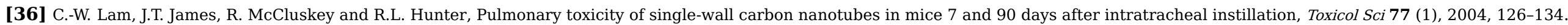

[37] Y. Wu, J.S. Hudson, Q. Lu, J.M. Moore, A.S. Mount, A.M. Rao, et al., Coating single-walled carbon nanotubes with phospholipids, J Phys Chem B 110 (6), 2006, 2475-2478.

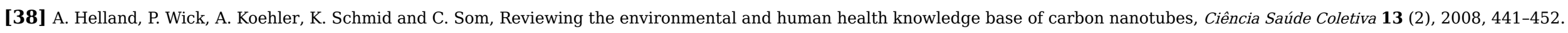

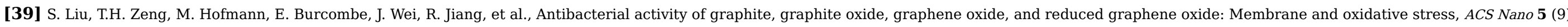
2011, 6971-6980.

[40] O.V. Kharissova, B.I. Kharisov and E.G. de Casas Ortiz, Dispersion of carbon nanotubes in water and non-aqueous solvents, RSC Adv 3 (47), 2013 , $24812-24852$.

[41] H.F. Lecoanet, J.-Y. Bottero and M.R. Wiesner, Laboratory assessment of the mobility of nanomaterials in porous media, Environ Sci Technol 38 (19), $2004,5164-5169$.

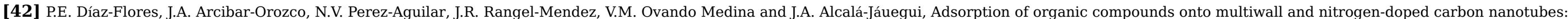
insights into the adsorption mechanisms, Water Air Soil Pollut 228 (4), 2017, 133.

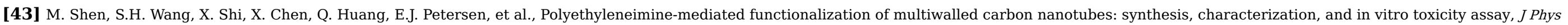
Chem C 113 (8), 2009, 3150-3156. 


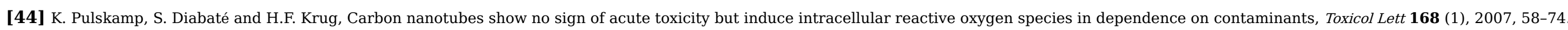

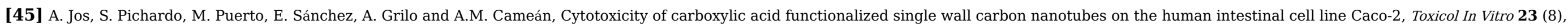
2009, 1491-1496.

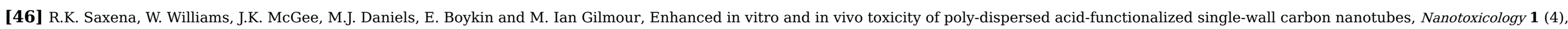
2007, 291-300.

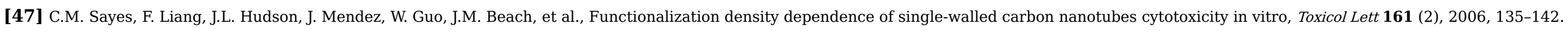

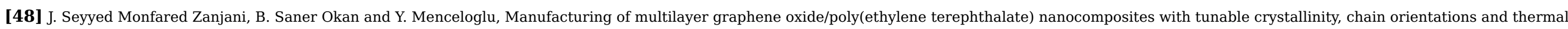
transitions, Mater Chem Phys 176 (Suppl. C), 2016, 58-67.

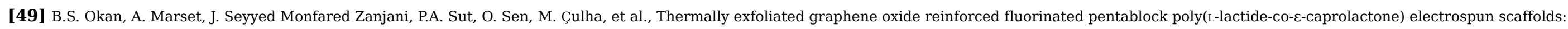
insight into antimicrobial activity and biodegradation, J Appl Polym Sci 133 (22), 2016, n/a-n/a.

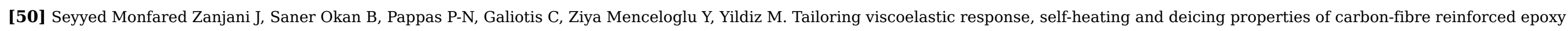
composites by graphene modification. Compos Part A Appl S. 106 (2018), pp. 1-10

Page 451

[51] V. Dhand, K.Y. Rhee, H. Ju Kim and D. Ho Jung, A comprehensive review of graphene nanocomposites: research status and trends, J Nanomater 2013, 2013 , 14.

[52] S.F. Kiew, L.V. Kiew, H.B. Lee, T. Imae and L.Y. Chung, Assessing biocompatibility of graphene oxide-based nanocarriers: a review, J Control Release 226, 2016 , 217-228.

[53] M. Segal, Selling graphene by the ton, Nat Nanotechnol 4, 2009, 612.

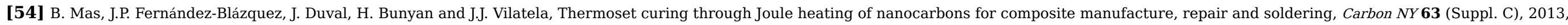
523-529.

[55] K. Zhang, K.C. Kemp and V. Chandra, Homogeneous anchoring of $\mathrm{TiO}_{2}$ nanoparticles on graphene sheets for waste water treatment, Mater Lett 81 (Suppl. C), 2012, 127-130.

[56] H. Chung, M.J. Kim, K. Ko, J.H. Kim, H.-A. Kwon, I. Hong, et al., Effects of graphene oxides on soil enzyme activity and microbial biomass, Sci Total Environ 514 (Suppl. C), 2015 , 307-313.

[57] P. Begum and B. Fugetsu, Induction of cell death by graphene in Arabidopsis thaliana (Columbia ecotype) T87 cell suspensions, J Hazard Mater 260 (Suppl. C), 2013, $1032-1041$.

[58] G. Eda, G. Fanchini and M. Chhowalla, Large-area ultrathin films of reduced graphene oxide as a transparent and flexible electronic material, Nat Nanotechnol 3, $2008,270$.

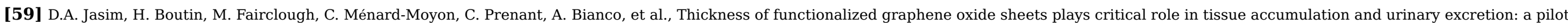
PET/CT study, Appl Mater Today 4 (Suppl. C), 2016, 24-30.

[60] O. Akhavan and E. Ghaderi, Toxicity of graphene and graphene oxide nanowalls against bacteria, ACS Nano 4 (10), 2010, 5731-5736.

[61] M. Venza, M. Visalli, C. Beninati, G.V. De Gaetano, D. Teti and I. Venza, Cellular mechanisms of oxidative stress and action in melanoma, Oxid Med Cell Longev 2015, 2015 , 481782.

[62] M. Hirtz, A. Oikonomou, T. Georgiou, H. Fuchs and A. Vijayaraghavan, Multiplexed biomimetic lipid membranes on graphene by dip-pen nanolithography, Nat Commun 4, 2013 , 2591.

[63] S. Liu, M. Hu, T.H. Zeng, R. Wu, R. Jiang, J. Wei, et al., Lateral dimension-dependent antibacterial activity of graphene oxide sheets, Langmuir 28 (33), 2012 , $12364-12372$. 
[64] B. Zhang, P. Wei, Z. Zhou and T. Wei, Interactions of graphene with mammalian cells: molecular mechanisms and biomedical insights, Adv Drug Deliv Rev 105 (Part B), 2016, 145-162.

[65] J. Zhao, Z. Wang, J.C. White and B. Xing, Graphene in the aquatic environment: adsorption, dispersion, toxicity and transformation, Environ Sci Technol 48 (17), 2014, 9995-10009.

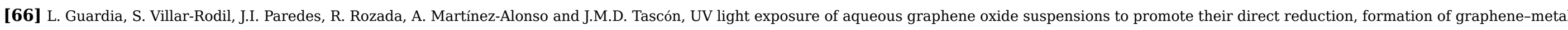
nanoparticle hybrids and dye degradation, Carbon NY 50 (3), 2012, 1014-1024.

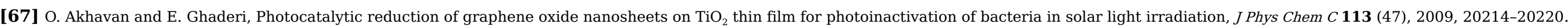

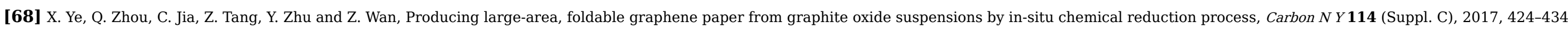

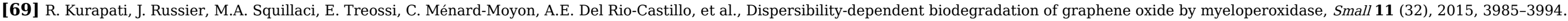

[70] M. Chen, X. Qin and G. Zeng, Biodegradation of carbon nanotubes, graphene, and their derivatives, Trends Biotechnol 35 (9), $2017,836-846$.

[71] G.P. Kotchey, B.L. Allen, H. Vedala, N. Yanamala, A.A. Kapralov, Y.Y. Tyurina, et al., The enzymatic oxidation of graphene oxide, ACS Nano 5 (3), $2011,2098-2108$.

Page 452

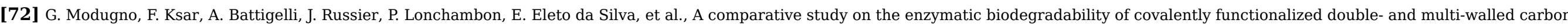
nanotubes, Carbon NY 100 (Suppl. C), 2016, 367-374.

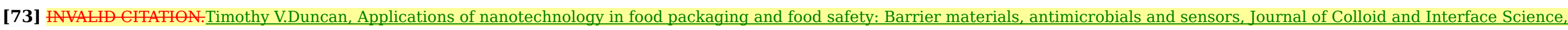
$363,1,2011,1-24$

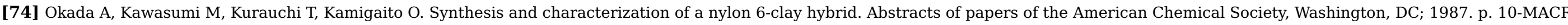

[75] A. Okada and A. Usuki, Twenty years of polymer-clay nanocomposites, Macromol Mater Eng 291 (12), 2006, 1449-1476.

[76] S. Sinha Ray and M. Okamoto, Polymer/layered silicate nanocomposites: a review from preparation to processing, Prog Polym Sci 28 (11), 2003, 1539-1641.

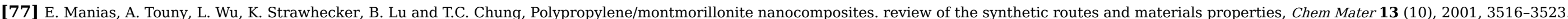

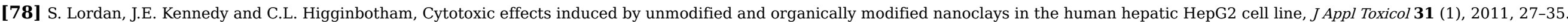

[79] S. Jayrajsinh, G. Shankar, Y.K. Agrawal and L. Bakre, Montmorillonite nanoclay as a multifaceted drug-delivery carrier: a review, J Drug Deliv Sci Technol 39 (Suppl. C), $2017,200-209$.

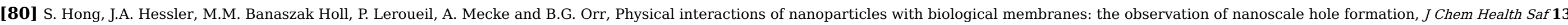
(3), 2006, 16-20

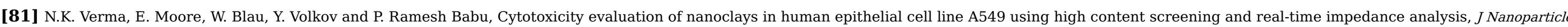
Res 14 (9), 2012, 1137

[82] M. Baek, J.-A. Lee and S.-J. Choi, Toxicological effects of a cationic clay, montmorillonite in vitro and in vivo, Mol Cell Toxicol 8 (1), $2012,95-101$.

[83] E.J. Murphy, E. Roberts, D.K. Anderson and L.A. Horrocks, Cytotoxicity of aluminum silicates in primary neuronal cultures, Neuroscience 57 (2), $1993,483-490$.

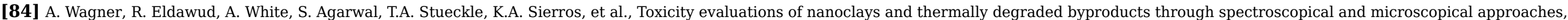


[85] Y. Xia, M. Rubino and R. Auras, Release of nanoclay and surfactant from polymer-clay nanocomposites into a food simulant, Environ Sci Technol 48 (23), $2014,13617-13624$.

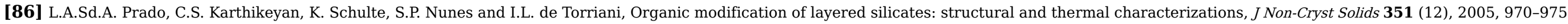

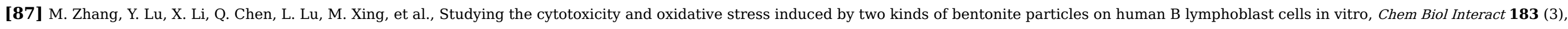
2010, 390-396.

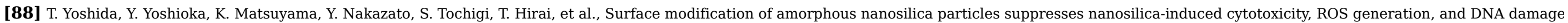
in various mammalian cells, Biochem Biophys Res Commun 427 (4), 2012, 748-752.

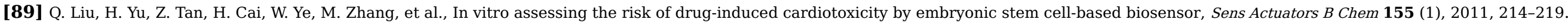

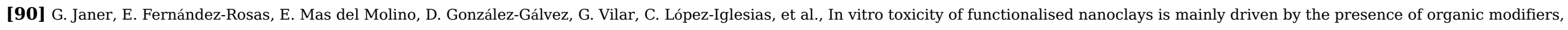
Nanotoxicology 8 (3), 2014, 279-294.

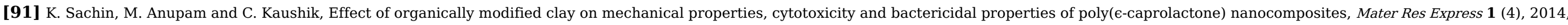
045302.

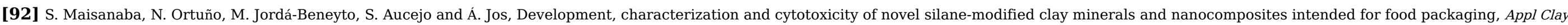
Sci 138 (Suppl. C), 2017, 40-47.

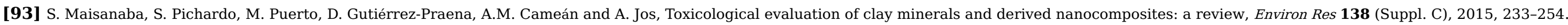

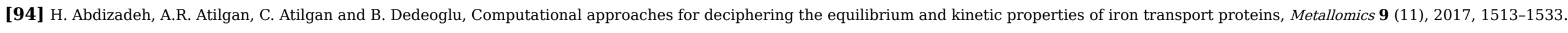

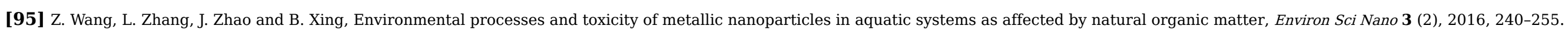

[96] Y.-F. Li and C. Chen, Fate and toxicity of metallic and metal-containing nanoparticles for biomedical applications, Small 7 (21), 2011 , $2965-2980$.

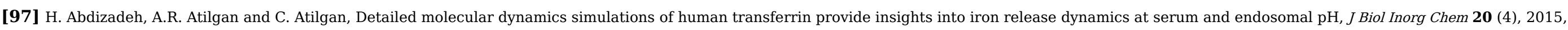
705-718.

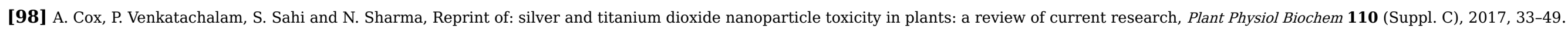

[99] F. Hong, X. Yu, N. Wu and Y.-Q. Zhang, Progress of in vivo studies on the systemic toxicities induced by titanium dioxide nanoparticles, Toxicol Res 6 (2), 2017, 115-133.

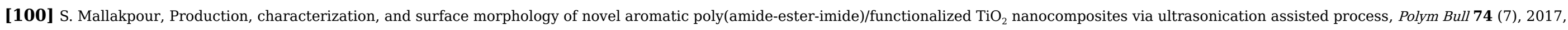
2465-2477.

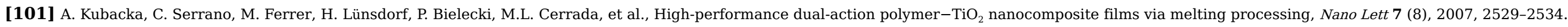

[102] G. Fu, P.S. Vary and C.-T. Lin, Anatase $\mathrm{TiO}_{2}$ nanocomposites for antimicrobial coatings, J Phys Chem B 109 (18), $2005,8889-8898$.

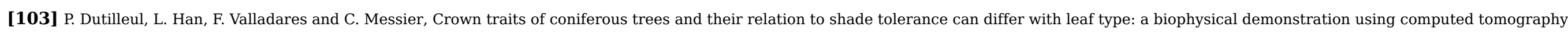


scanning data, Front Plant Sci 6, 2015, 172.

[104] G. Kuku and M. Culha, Investigating the origins of toxic response in $\mathrm{TiO}_{2}$ nanoparticle-treated cells, Nanomaterials 7 (4), $2017,83$.

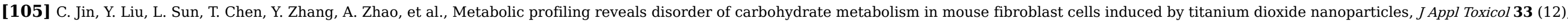
2013, 1442-1450.

[106] C.-Y. Jin, B.-S. Zhu, X.-F. Wang and Q.-H. Lu, Cytotoxicity of titanium dioxide nanoparticles in mouse fibroblast cells, Chem Res Toxicol 21 (9), $2008,1871-1877$.

[107] E. Demir, N. Kaya and B. Kaya, Genotoxic effects of zinc oxide and titanium dioxide nanoparticles on root meristem cells of Allium cepa by comet assay, Turk J Biol 38 (1), 2014 , 31-39.

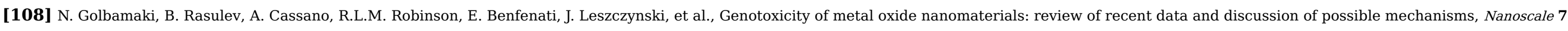
(6), 2015, 2154-2198.

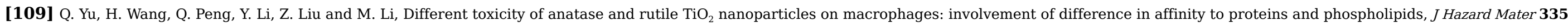
2017, 125-134.

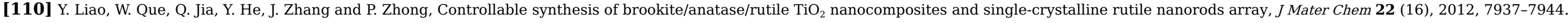

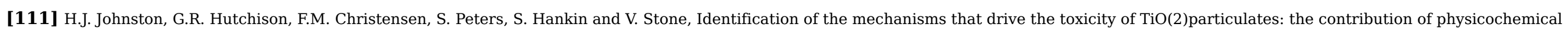
characteristics, Part Fibre Toxicol 6, 2009, 33-.

[112] C. Jin, Y. Tang, F.G. Yang, X.L. Li, S. Xu, X.Y. Fan, et al., Cellular toxicity of $\mathrm{TiO}_{2}$ nanoparticles in anatase and rutile crystal phase, Biol Trace Elem Res 141 (1), 2011 , 3-15.

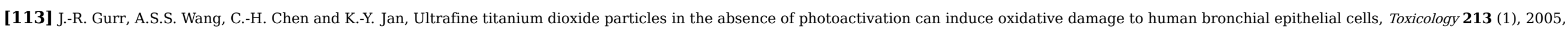
66-73.

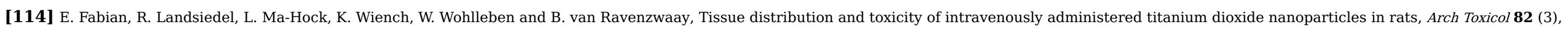
2008, 151-157.

[115] J. Chen, X. Dong, J. Zhao and G. Tang, In vivo acute toxicity of titanium dioxide nanoparticles to mice after intraperitioneal injection, J Appl Toxicol 29 (4), $2009,330-337$.

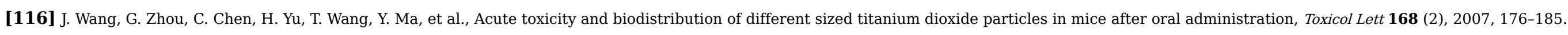

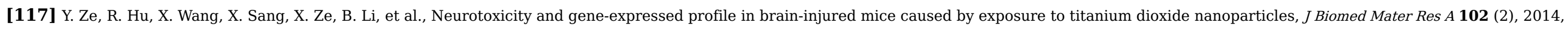
$470-478$.

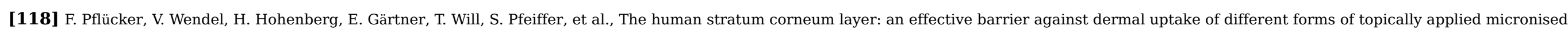
titanium dioxide, Skin Pharmacol Physiol 14 (Suppl. 1), 2001, 92-97.

[119] A.O. Gamer, E. Leibold and B. van Ravenzwaay, The in vitro absorption of microfine zinc oxide and titanium dioxide through porcine skin, Toxicol In Vitro 20 (3), 2006 , 301-307.

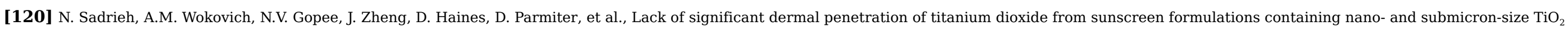
particles, Toxicol Sci 115 (1), 2010, 156-166. 
[121] M.üller G. Bennat, Skin penetration and stabilization of formulations containing microfine titanium dioxide as physical UV filter, Int J Cosmet Sci 22 (4), $2000,271-283$.

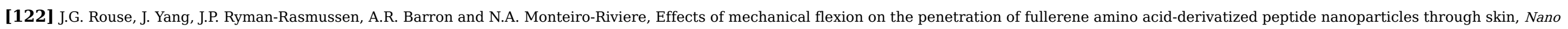
Lett 7 (1), 2007, 155-160.

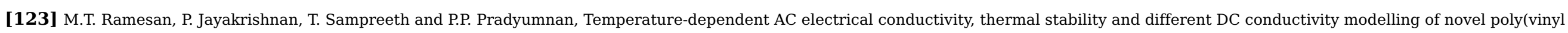
cinnamate)/zinc oxide nanocomposites, J Therm Anal Calorim 129 (1), 2017, 135-145.

[124] Y. Qi, J. Zhang, S. Qiu, L. Sun, F. Xu, M. Zhu, et al., Thermal stability, decomposition and glass transition behavior of PANI/NiO composites, J Therm Analy Calorim 98 (2), 2009 , 533.

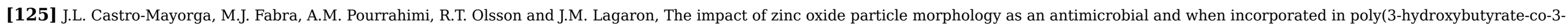
hydroxyvalerate) films for food packaging and food contact surfaces applications, Food Bioprod Process 101 (Suppl. C), $2017,32-44$.

[126] Y. Zhang, S. Zhuang, X. Xu and J. Hu, Transparent and UV-shielding ZnO@PMMA nanocomposite films, Opt Mater 36 (2), $2013,169-172$.

[127] J. Anderson and G.Vd.W. Chris, Fundamentals of zinc oxide as a semiconductor, Rep Prog Phys 72 (12), 2009, 126501.

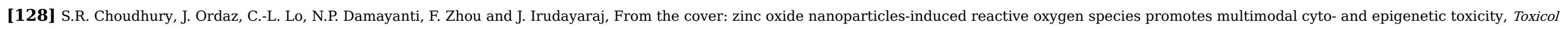
SCi 156 (1), 2017, 261-274.

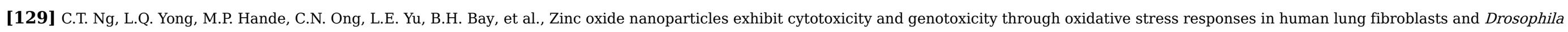
melanogaster, Int J Nanomed 12, 2017, 1621-1637.

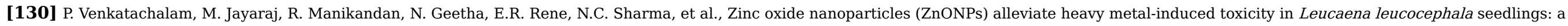
physiochemical analysis, Plant Physiol Biochem 110 (Suppl. C), 2017, 59-69.

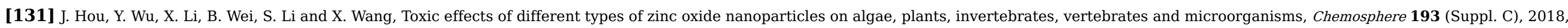
852-860.

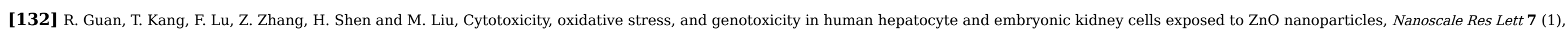
$2012,602$.

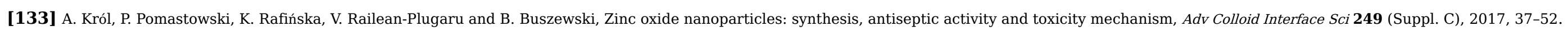

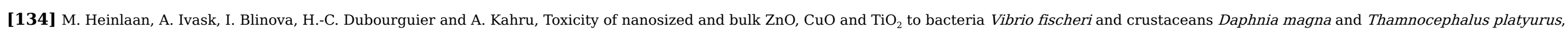
Chemosphere 71 (7), 2008, 1308-1316.

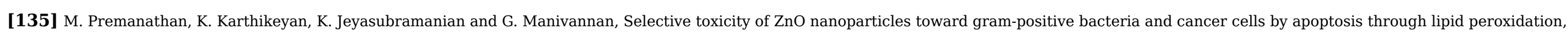
Nanomedicine 7 (2), 2011, 184-192.

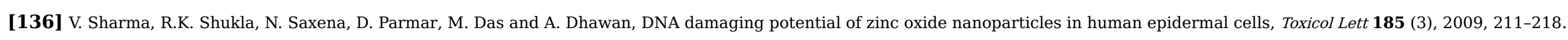

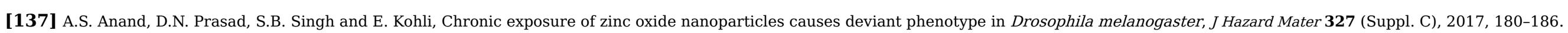




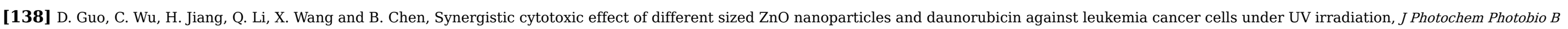
Bio 93 (3), 2008, 119-126.

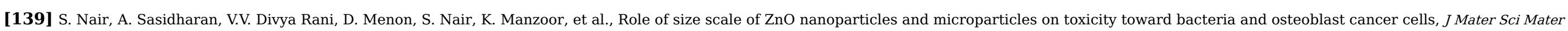
Med 20 (1), 2008, 235.

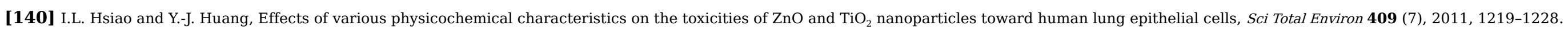

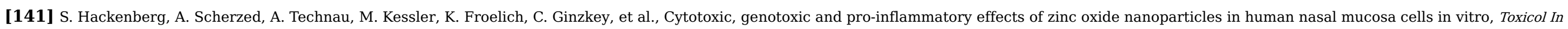
Vitro 25 (3), 2011, 657-663.

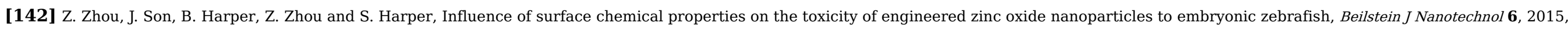
1568-1579.

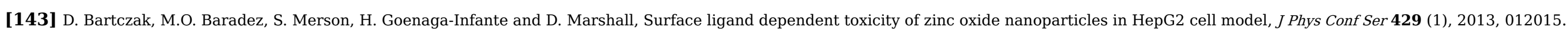

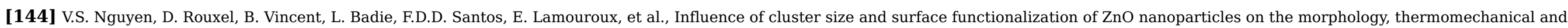
piezoelectric properties of P(VDF-TrFE) nanocomposite films, Appl Surf Sci 279 (Suppl. C), 2013, 204-211.

Page 456

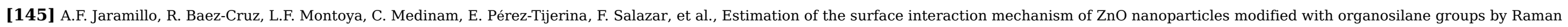
spectroscopy, Ceram Int 43 (15), 2017, 11838-11847.

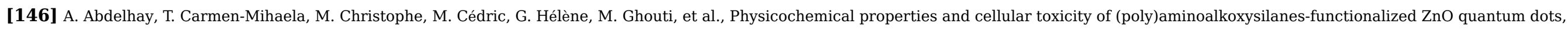
Nanotechnology 23 (33), 2012, 335101.

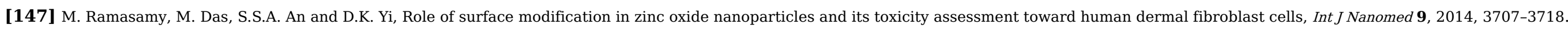

[148] I.L. Hsiao and Y.-J. Huang, Titanium oxide shell coatings decrease the cytotoxicity of ZnO nanoparticles, Chem Res Toxicol 24 (3), 2011, 303-313.

[149] M. Luo, C. Shen, B.N. Feltis, L.L. Martin, A.E. Hughes, P.F.A. Wright, et al., Reducing ZnO nanoparticle cytotoxicity by surface modification, Nanoscale 6 (11), 2014, 5791-5798.

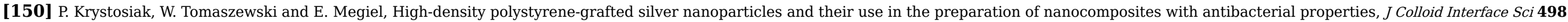
(Suppl. C), 2017, 9-21.

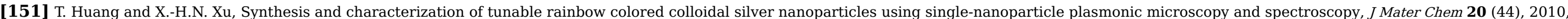
9867-9876.

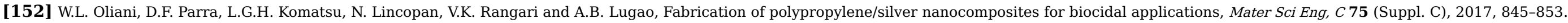

[153] K. Kawata, M. Osawa and S. Okabe, In vitro toxicity of silver nanoparticles at noncytotoxic doses to HepG2 human hepatoma cells, Environ Sci Technol 43 (15), 2009, 6046-6051.

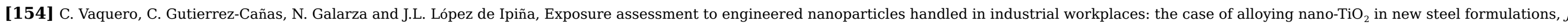
Aerosol Sci 102 (Suppl. C), 2016, 1-15. 
[155] S. Kim, J.E. Choi, J. Choi, K.-H. Chung, K. Park, J. Yi, et al., Oxidative stress-dependent toxicity of silver nanoparticles in human hepatoma cells, Toxicol In Vitro 23 (6), 2009, 1076-1084.

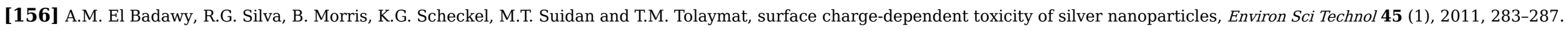

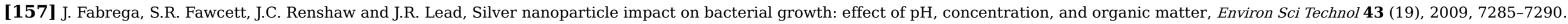

[158] O. Choi, T.E. Clevenger, B. Deng, R.Y. Surampalli, L. Ross and Z. Hu, Role of sulfide and ligand strength in controlling nanosilver toxicity, Water Res 43 (7), 2009, 1879-1886.

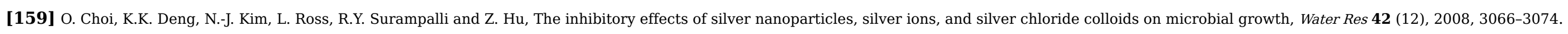

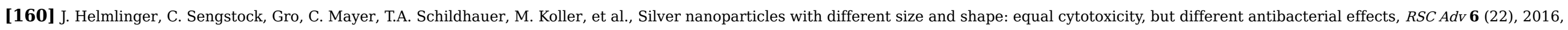
18490-18501.

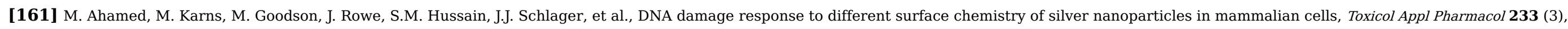
$2008,404-410$.

[162] M. Rai, A. Yadav and A. Gade, Silver nanoparticles as a new generation of antimicrobials, Biotechnol Adv 27 (1), $2009,76-83$.

[163] Z.-M. Xiu, Q.-B. Zhang, H.L. Puppala, V.L. Colvin and P.J.J. Alvarez, Negligible particle-specific antibacterial activity of silver nanoparticles, Nano Lett 12 (8), 2012, $4271-4275$.

Page 457

[164] P.V. Asharani, W. Yi Lian, G. Zhiyuan and V. Suresh, Toxicity of silver nanoparticles in zebrafish models, Nanotechnology 19 (25), $2008,255102$.

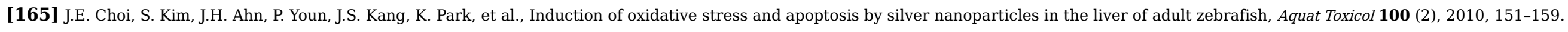

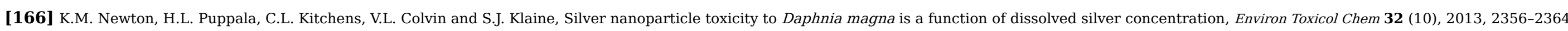

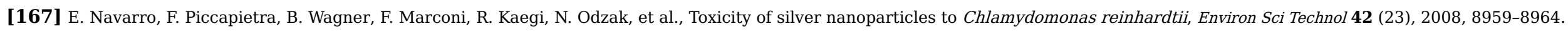

[168] A. Brandelli, L.F.W. Brum and J.H.Z. dos Santos, Nanostructured bioactive compounds for ecological food packaging, Environ Chem Lett 15 (2), 2017 , 193-204.

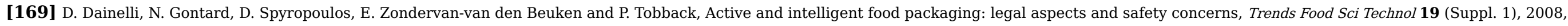
S103-S112.

[170] M. Vanderroost, P. Ragaert, F. Devlieghere and B. De Meulenaer, Intelligent food packaging: the next generation, Trends Food Sci Technol 39 (1), $2014,47-62$.

[171] B. Tan and N.L. Thomas, A review of the water barrier properties of polymer/clay and polymer/graphene nanocomposites, J Memb Sci 514 (Suppl. C), $2016,595-612$.

[172] Y. Cui, S. Kumar, B. Rao Kona and D. van Houcke, Gas barrier properties of polymer/clay nanocomposites, RSC AdV 5 (78), 2015, 63669-63690.

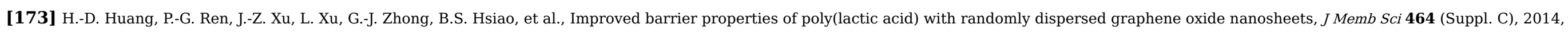
$110-118$.

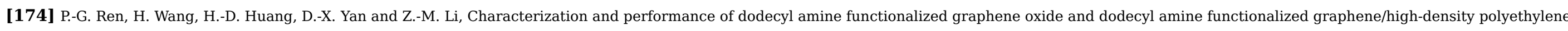
nanocomposites: a comparative study, J Appl Polym Sci 131 (2), 2014, n/a-n/a.

[175] M. Alexandre and P. Dubois, Polymer-layered silicate nanocomposites: preparation, properties and uses of a new class of materials, Mater Sci Eng R 28 (1), $2000,1-63$. 
[176] A. Kalendova, D. Merinska, J.F. Gerard and M. Slouf, Polymer/clay nanocomposites and their gas barrier properties, Polym Compos 34 (9), 2013, 1418-1424.

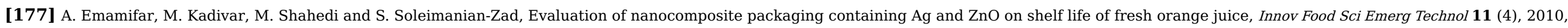
$742-748$.

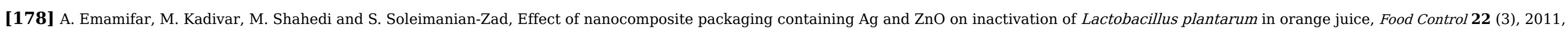
408-413.

[179] C. Damm, M. Neumann and H. Münstedt, Properties of nanosilver coatings on polymethyl methacrylate, Soft Mater 3 (2-3), 2005, 71-88.

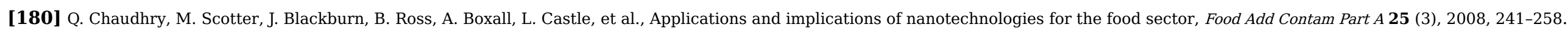

[181] G. Mauriello, E. De Luca, A. La Storia, F. Villani and D. Ercolini, Antimicrobial activity of a nisin-activated plastic film for food packaging, Lett Appl Microbiol 41 (6), 2005 , 464-469.

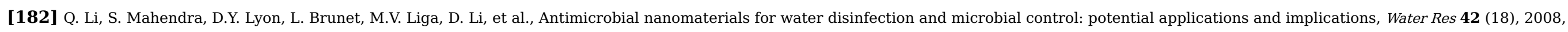
4591-4602.

[183] A. Emamifar, Applications of antimicrobial polymer nanocomposites in food packaging, In: A. Hashim, (Ed), Advances in nanocomposite technology, 2011, InTech, Rijeka, [chapter 13].

[184] M.B. Shiflett and H.C. Foley, Ultrasonic deposition of high-selectivity nanoporous carbon membranes, Science 285 (5435), 1999, $1902-1905$.

[185] T.C. Merkel, B.D. Freeman, R.J. Spontak, Z. He, I. Pinnau, P. Meakin, et al., Ultrapermeable, reverse-selective nanocomposite membranes, Science 296 (5567), 2002, 519-522.

[186] J. Yin and B. Deng, Polymer-matrix nanocomposite membranes for water treatment, J Memb Sci 479, 2015, 256-275.

[187] L.Y. Ng, A.W. Mohammad, C.P. Leo and N. Hilal, Polymeric membranes incorporated with metal/metal oxide nanoparticles: a comprehensive review, Desalination 308, 2013, 15-33.

[188] H. Cong, M. Radosz, B.F. Towler and Y. Shen, Polymer-inorganic nanocomposite membranes for gas separation, Sep Purif Technol 55 (3), $2007,281-291$.

[189] M. Ulbricht, Advanced functional polymer membranes, Polymer (Guildf) 47 (7), 2006, 2217-2262.

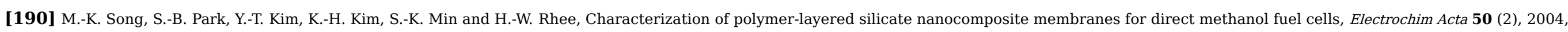
639-643.

[191] K. Jian, P.N. Pintauro and R. Ponangi, Separation of dilute organic/water mixtures with asymmetric poly(vinylidene fluoride) membranes, J Memb Sci 117 (1), $1996,117-133$.

[192] T.-H. Bae and T.-M. Tak, Effect of $\mathrm{TiO}_{2}$ nanoparticles on fouling mitigation of ultrafiltration membranes for activated sludge filtration, J Memb Sci 249 (1), 2005 , 1-8.

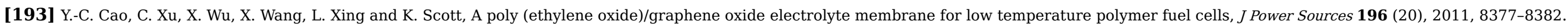

[194] M. Pumera, Graphene-based nanomaterials for energy storage, Energy Environ Sci 4 (3), 2011, 668-674.

[195] M.U. Niemann, S.S. Srinivasan, A.R. Phani, A. Kumar, D.Y. Goswami and E.K. Stefanakos, Nanomaterials for hydrogen storage applications: a review, J Nanomater 2008, $2008,9$.

[196] C. Liu, F. Li, L.-P. Ma and H.-M. Cheng, Advanced materials for energy storage, Adv Mater 22 (8), 2010, E28-E62.

[197] A.S. Aricò, P. Bruce, B. Scrosati, J.-M. Tarascon and W. van Schalkwijk, Nanostructured materials for advanced energy conversion and storage devices, Nat Mater 4, $2005,366$. 
[198] M. Dincă and J.R. Long, Hydrogen storage in microporous metal-organic frameworks with exposed metal sites, Angew Chem Int Ed 47 (36), $2008,6766-6779$.

[199] Q. Zhang, E. Uchaker, S.L. Candelaria and G. Cao, Nanomaterials for energy conversion and storage, Chem Soc Rev 42 (7), $2013,3127-3171$.

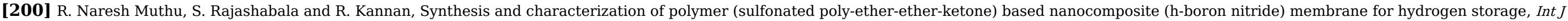
Hydrogen Energy 40 (4), 2015, 1836-1845.

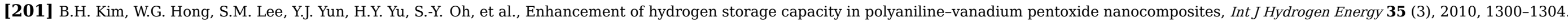

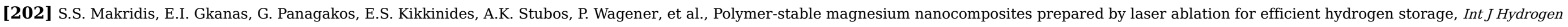
Energy 38 (26), 2013, 11530-11535. Abstract

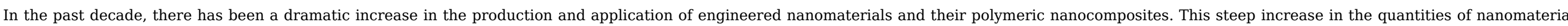

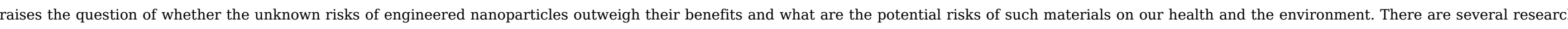

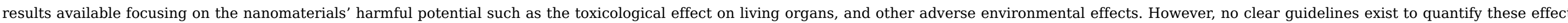
and to prevent unplanned environmental costs.

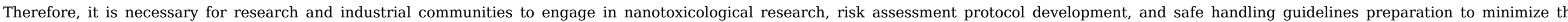

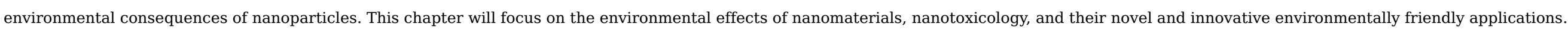
Key words: Nanoparticles; polymeric nanocomposites; nanotoxicology; environment; nanocomposites application.

\section{Queries and Answers}

Query: Please check the edits made to the sentence: "Furthermore, it is observed ... effect on cells " and amend if necessary.

Answer: Modifications have been made.

Query: Please check the edits made to the sentence: " In addition to the toxicity ... with ZnO nanoparticles themselves" and amend if necessary.

Answer: Modifications have been made.

Query: Please check the edits made to the sentence: The state of the dispersion ... modification of particles" and amend if necessary.

Answer: it seems OK.

Query: Please provide full reference details for Refs. [9,50]

Answer: [9] J.S.M. Zanjani, S. Okan Burcu, Y. Menceloglu, M. Yildiz

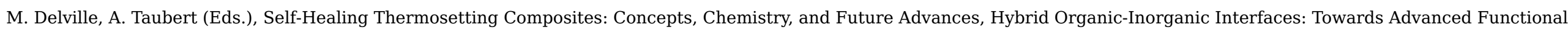
Materials, Wiley (2017).(CH3) DOI: 10.1002/9783527807130.ch3

Query: Please provide full reference details for Ref. [73]. Else, delete and renumber the rest.

Answer: updated.

Query: There are five parts (a) to (e) of Figure 14-2, but these are not defined in the caption. Please provide a definition for each part.

Answer: updated.

Query: Please provide better quality images for figures 14-1, 14-3, 14-5, 14-6, 14-7, 14-10.

Answer: The best available quality images are attached. 